\title{
Writing in Turns: \\ An Analysis of Scribal Hands in the Bamboo Manuscript Suan shu shu 等數書 (Writings on Mathematical Procedures) from Zhangjiashan tomb no. 247
}

\author{
Daniel Patrick Morgan 墨子涵 \\ Karine Chemla 林力娜”
}

\begin{abstract}
Refining our previous study in Jianbo 簡帛 12 (2016), this article examines the back-and-forth between scribal hands in the Suan shu shu 等數術 from Zhangjiashan 張家山 M247 (sealed $\geq 186$ BCE). Introducing an improved methodology, we establish a link between one the Suan shu shu's scriptors and four other manuscripts in the same tomb, offering a hand-informed reading of the former to hypothesize what this means.
\end{abstract}

Keywords: Zhangjiashan M247, Suan shu shu 笄數術, handwriting analysis, history of mathematics, mingqi 明器

摘要 : 以『簡帛』第 12 輯 ( 2016 年 $)$ 的原作為基礎, 本文將張家山 247 號漢墓
『等數術』寫手的輪流交替加以分析。在介紹我們對原有方法論的改進後, 本文把
『等數術』的兩位寫手之一與隨葬的四種文本串聯, 再由字跡、文意對讀解釋其意
味。

關鍵詞：張家山 M247，『算數術』，字迹分析，數學史，明器

\section{Introduction}

The excavation of Zhangjiashan 張家山 tomb no. 247, Jiangling County, Hubei, in the winter of 1983-84 revealed a manuscript corpus of eight texts on law, medicine, sports, philosophy, and mathematics (Table 1). Dubbed *Lipu 曆譜 or "calendar," the presence of a seventeen-year lunation table for 202-186 B.C.E. has led archeologists to conclude that M247 was sealed "in 186 B.C.E. or shortly after." Two personal entries in this lunation table- " $[\mathrm{I}]$ Xin/newly surrendered to the Han” 新降為漢 in 202 B.C.E. (slip 2) and "[I] retired from office due to illness" 病免 in 194 B.C.E. (slip 10) - have led furthermore, and in fitting with the size and contents of the tomb, to the conclusion that the occupant was an educated, low-level official retired from the local government. ${ }^{2}$ Our interest in such an eclectic corpus is usually to pluck a single text from Table 1 to read with others of its kind in "the history of $x$."

\footnotetext{
* The research leading to these results has received funding from the European Research Council under the European Union's Seventh Framework Programme (FP7/2007-2013) / ERC Grant agreement n. 269804.

${ }^{1}$ Zhangjiashan ersiqi hao Han mu zhujian zhengli xiaozu 張家山二四七號 漢墓整理小組, Zhangjiashan Han mu zhujian (ersiqi hao mu) 張家山漢墓竹簡 (三四七號墓) (Beijing: Wenwu chubanshe, 2001), 1.

${ }^{2}$ For an overview of the discovery, excavation, conservation, and publication of the contents of Zhangjiashan M247, see Anthony J. Barbieri-Low and Robin D. S. Yates, Law, State, and Society in Early Imperial China: A Study with Critical Edition and Translation of the Legal Texts from Zhangjiashan Tomb No. 247 (Leiden: Brill, 2015), 3-18.
} 


\begin{tabular}{lllr}
\hline Title & Subject & Slips \\
\hline 1 & Ernian lüling 二年律令 & law & 526 \\
2 & Gai Lu 蓋盧 & military philosophy & 55 \\
3 & *Lipu 曆譜 & calendar & 18 \\
4 & Mai shu 脈書 & medicine & 66 \\
5 & *Qiance 遣策 & tomb inventory & 41 \\
6 & Suan shu shu 等數書 & mathematics & 190 \\
7 & Yin shu 引書 & sport & 112 \\
8 & Zou yan shu 奏獻書 & law & 228 \\
\hline
\end{tabular}

Table 1: Zhangjiashan M247 manuscript corpus. Asterisks indicate titles coined by the editors.

The * Lipu however should remind us that the questions we address concerning any one of these manuscripts may have answers lying but centimeters away in the bundle.

Codicologically, the most interesting of the bamboo manuscripts from Zhangjiashan M247 is probably the Suan shu shu 算 數書 (Writings on Mathematical Procedures). ${ }^{3}$ The support, comprised of $190 \mathrm{slips}, \approx 30 \mathrm{~cm}$ long, is divided in four by three binding cords into a 'body' $\approx 26.5 \mathrm{~cm}$ in height and upper and lower margins of $\approx 1.75 \mathrm{~cm}$ each. All three feature writing. In the upper margin, one finds 69 headings corresponding with paragraph breaks in the body. In the lower margin, there are two slips where the body spills over and, more importantly, fourteen "signatures" by a certain Yang 楊 and Wang 王 noting (in two places) what they had "already checked" 已倠隹. (A certain Jing 競 likewise appears once, on slip 83, just above the lower binding cord). ${ }^{4}$ This is the first time that we have found traces of the sort of "checking" in a Qin-Han tomb text, the editors hypothesizing that Yang, Wang, (and Jing) represent "either copyists or collators." In the body, Ōkawa Toshitaka's 大川俊隆 team furthermore notes what appears to be a transition of hands (slips 10-11), bringing the number of the manuscript's potential contributors up to five-and that's before we get to the headings. ${ }^{6}$ The headings, one notes, do not

\footnotetext{
${ }^{3}$ For the Suan shu shu, we use the photographs and critical edition of Ōkawa's research group (Chōkazan Kankan Sansūsho kenkyūkai 張家山漢簡「算 數書」研究會) in Kankan Sansūsho: Chügoku saiko no sūgakusho 漢簡「算數 書」: 中國最古の數學書 (Kyōto: Hōyū shoten, 2006). Other major studies referenced are Peng Hao 彭浩, Zhangjiashan Han jian Suan shu shu zhushi 張 家山漢簡『等數書』註釋 (Beijing: Kexue chubanshe, 2001); Guo Shirong 郭 世榮, “Suan shu shu kanwu”『算數書』勘誤, Neimenggu shifan daxue xuebao (ziran kexue Hanwen ban) 內蒙古師範大學學報（自然科學漢文版） 30.3 (2001): 276-85; Guo Shuchun 郭書春, “Suan shu shu jiaokan”『算數書』校 勘, Zhongguo keji shiliao 中國科技史料 22.3 (2001): 202-19; Christopher Cullen, The Suàn Shù Shū 算數書 “Writings on Reckoning”: A Translation of a Chinese Mathematical Collection of the Second Century BC, with Explanatory Commentary (Cambridge: Needham Research Institute, 2004); Joseph W. Dauben, “算書書 Suan Shu Shu, a Book on Numbers and Computations: English Translation with Commentary," Archive for History of Exact Sciences 62 (2008): 91-178.

${ }_{5}^{4}$ Kankan Sansūsho, 67.

${ }^{5}$ Zhangjiashan Han mu zhujian (ersiqi hao mu), 249 n4.

${ }^{6}$ Kankan Sansūsho, 150n4.
} 
appear in the parallel Yuelu Academy manuscript $S h u$ 數, raising the issue as to whether they were added by a reader. ${ }^{7}$

Another interesting fact about the Suan shu shu is that its order is a total mystery. The text is comprised of 69 sections beginning each with a heading in the upper margin and ending with a "leaveblank" 留白 paragraph break in the body. As such, each section forms an independent textual and physical whole, and while we can confidently restore the slip-order within each section, that between sections is up for debate. To restore the section-order, our only recourse thus far has been the "Excavated Position Diagram" 出土位置示意圖 at the end of the published volume. ${ }^{8}$ The diagram, however, is a mystery: for the Suan shu shu, it is missing ten slips (H181-90), and what appear as neat physical layers on the diagram would place lines from integral problems hither and thither throughout the text. ${ }^{9}$ Whatever the reasons for this, the inconsistencies of this diagram have opened the door to radically different section-ordering. Ökawa's team, for example, places the title slip last, reading inside-out from “Shao guang” 少廣 (slips 164-82), whereas Peng Hao 彭浩 places it six slips from the opening, moving outside-in from "Xiang cheng" 相乘 (slips 1-6). ${ }^{10}$ Normally, one would go about looking for scribal hands in blocks, but the blocks of the Suan shu shu pose a special challenge: they are small, and they can be shuffled in whatever order you like.

In this article, we submit the Suan shu shu to graphological analysis so as to determine the number and distribution of hands therein and their relation to the manuscript's textual order. We begin with a look at the headings, body, and "signatures," which will reveal a clear identification of two hands alternating back and forth - back and forth between heading and body and back and forth within the body. (The "signatures," sadly, do not provide us much by way of positive identification, but we will examine the

\footnotetext{
${ }^{7}$ Shu is published in Zhu Hanmin 朱漢民 and Chen Songchang 陳松長, eds., Yuelu shuyuan cang Qin jian (er) 嶽麓書院藏秦簡 (武) (Shanghai: Shanghai cishu chubanshe, 2011).

${ }^{8}$ Zhangjiashan Han mu zhujian (ersiqi hao mu), 322.

${ }^{9}$ Mo Zihan 墨子涵 (Daniel P. Morgan) and Lin Lina 林力娜 (Karine Chemla), "Ye you lunzhe xiede: Zhangiiashan Han jian Suan shu shu xieshou yu bianxu chutan”也有輪着寫的：張蒙山漢簡『等數書』寫手與編序初探, Jianbo 簡帛 12 (2016): 235-51 (pp. 243-45). For similar problems concerning the Gai Lu manuscript, see Olivia Milburn, “'Gai Lu': A Translation and Commentary on a Yin-Yang Military Text Excavated from Tomb M247, Zhangjiashan," Early China 33/34 (2010): 101-40 (pp. 104-5n17). For similar problems concerning the Ernian lüling, see Liu Xiaoyi 劉曉芸 and You Yifei 游逸 飛, “Cong chutu weizhi yu neirong chongpai Zhangjiashan Han jian Ernian lüling ‘Chuanshi lü’ de lüwen cixu” 從出王位置與內容重排張家山漢簡『二 年律令. 傳食律』的律文次序, Bamboo and Silk Manuscripts, August 14, 2013, http://www.bsm.org.cn/show_article.php?id=1880. One notes that the *Lipu, whose slip-order is the surest of the entire corpus, reveals yet further inconsistencies.

${ }^{10}$ Kankan Sansūsho, 11-13; Peng Hao, Zhangjiashan Han jian Suan shu shu zhushi, 2. For yet another stab at section-ordering, see Liu Jinhua 劉金華, "Shishuo Zhangiiashan Han jian Suan shu shu de wenben jiegou wenti" 試說張 家山漢簡『算數書』的文本結構問題, Bamboo and Silk Manuscripts, December 8, 2003, http://www.jianbo.org/admin3/list.asp?id=1078.
} 
sort of proofreading to which the manuscript attests and with which Yang, Wang, and Jing seem to have been charged). From there, we will step back to look for some pattern of distribution in terms of textual contents and other hands in the Zhangjiashan M247 corpus. Here we will come up dry as concerns restoring the text's original order, but Hand B, we learn, is not alone in this horde. After identifying Suan shu shu B with four other manuscripts in this tomb, we will then turn examine the mid-section points at which the Suan shu shu changes hands in the hope of gleaning some information about B. There is a pattern, it turns out, to the back and forth between hands, and we will speculate in the conclusion about what it means.

\section{Graphological Analysis}

\section{Upper margin}

Third and second-century B.C.E. literature tends to feature two types of section/chapter headings: those that summarize the contents of a given piece and those that simply repeat the opening characters. The Suan shu shu is no exception in this regard (\| indicates the position of the binding, and $\rightarrow$ a terminal blank):

\footnotetext{
矰（增）減分\|增分者，增其子 $\llcorner$; 減分者，增其母。 $\rightarrow\|\rightarrow\|$ Increasing or Decreasing Parts: To increase parts (derived from cutting units into "parts"), one increases the corresponding numerator $\llcorner$; to decrease parts, one increases the corresponding denominator. II (slip 13).
}

約分||約分術曰：...

Simplifying Parts: The procedure for simplifying parts: ... (slip 17).

The only thing that is exceptional about these headings, one might say, is how very repetitive of the body text they are. Repetition, however, provides us the ideals means for determining whether the handwriting in the headings and the body are the same. As a first step we therefore made a comparison of the headings with the same graphs as they appear in the body of the very slips and sections that they head, a representative selection of which you can find in Figure 1.

The contrast was striking (Figure 1, exp. 1-10). One sees, first of all, a clear difference of style and brush habits between the long/short terminal strokes on characters like 材 and 負, between the left-right, top-bottom symmetry of characters like 增 and 材, and between the systematically upward/downward slant of horizontal lines. One also sees a difference at the level of graph structure between 增 and 矰 for "increase," 睘 and 圆 for "round," 氽 and 䰁 for "lacquer," and 吳 and 誤 for “error” (exp. 1-6). Setting matters of "script," "writing level," and cursive aside, as 


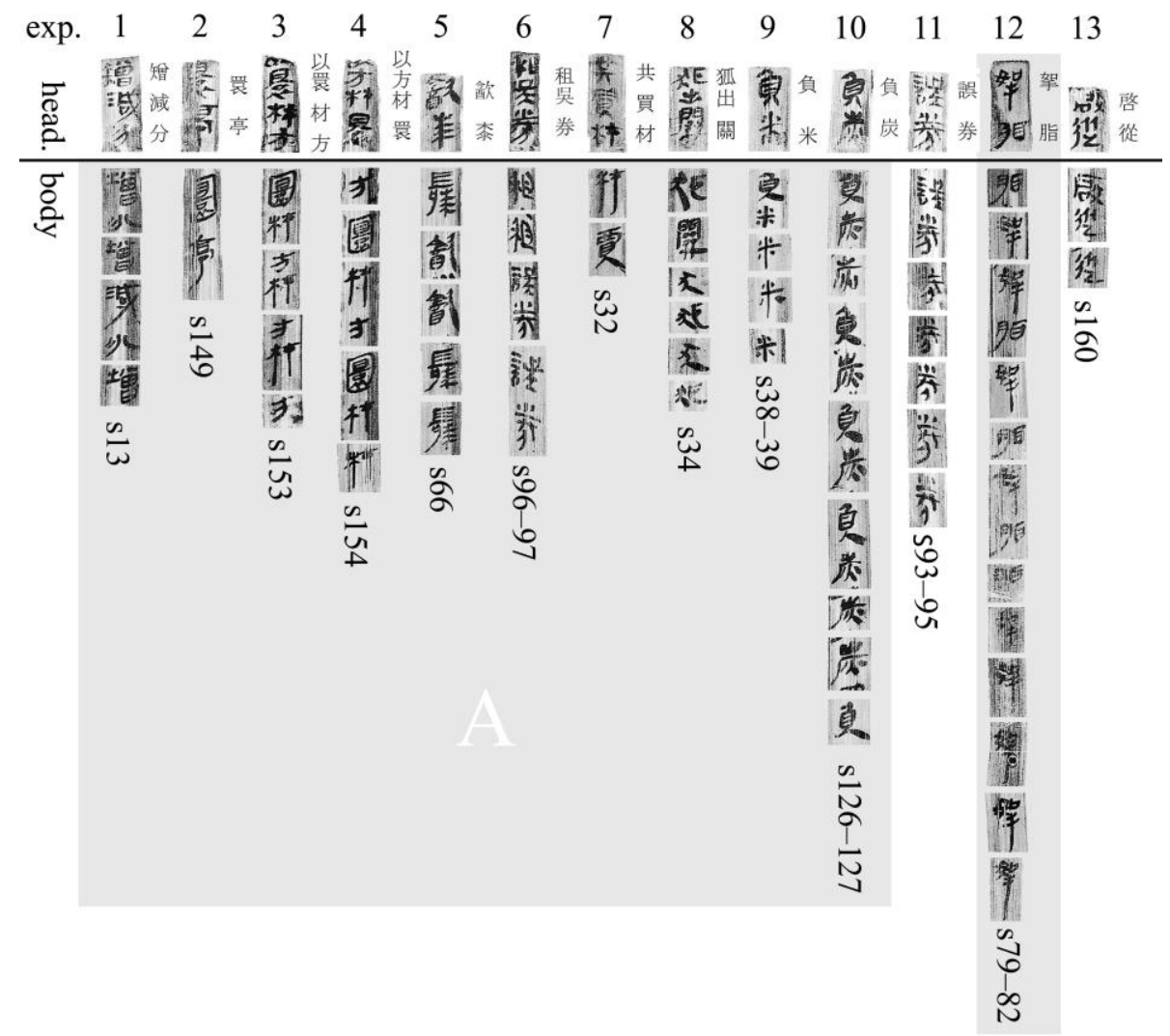

Figure 1: Heading-body comparison. "Hand A" is highlighted in grey, the rest belonging to "Hand B."

well as matters of "hands," let us simply identify handwriting A, in grey, as distinct from a handwriting B, in white.

The difference in hands between heading and body we had anticipated, but not the distribution. We had originally conceived of the problem in terms of binaries reasoned from common sense: the headings and the body are either the same, or they are different; the headings either come first, or they come last. Instead, it turns out that while it is usually A in the body, and B in the headings, A appears in at least one heading (Figure 1, exp. 12), and B in numerous parts of the body (exp. 11, 12). From this, we reasoned that $\mathrm{A}$ must have preceded B: otherwise, how could B have known where to place the headings? "Must have" scenarios reasoned from "common sense," however, are not an infallible guide to secondcentury B.C.E. writing practices.

\section{Body}

Having realized that the question of hands extended from the headings into the body, the next step was to explore how we might map the manuscript into $\mathrm{A}$ and $\mathrm{B}$ if not along the binding. To this end we turned for inspiration to Mathias Richter and Li Songru's 李松 
儒 methodological reflections on handwriting analysis. ${ }^{11}$ Adapting their reflections into practice involved considerable trial and error on our part, so allow us to briefly explain how we arrived at a working procedure for the Suan shu shu.

We began by compiling character forms from a PDF version of the manuscript, copy-and-pasting each occurrence of an individual graph in the body into a line-up. We did not know what to select for. Having read from Richter that "in the case of Chinese texts, analysis must concentrate on those characters that occur most often in the examined documents as well as on especially frequent characters components," we prioritized prevalent graphs like 之 “it,” 從 “from," 乘 “multiply," and 術 "procedure," 12 throwing in a couple more that simply struck us as "really different" as per Figure 1. After days of fruitless sorting it became apparent that frequency alone was insufficient as a criterion of selection. The problem was that the more prevalent the character form, the more it tended to vary, and, the simpler, the harder this variation was to grasp. Graphs like 之, 從, and 乘 changed every couple of centimeters (see Figure 2), and 術 “procedure” occurs on a single slip as 政, 福,

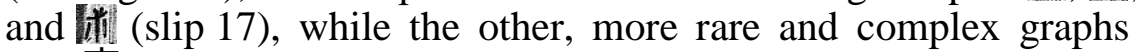
like 實 "dividend" remained completely stable. It is not surprising that we were thrown off by a character like $之$, as we later learned, given that the later calligraphic tradition indeed stresses variation for reasons of aesthetics.

In the end we subordinated the criterion of frequency to that of consistency, because it is ultimately in line-ups of consistent character forms that one sees a consistent difference in character forms. A line-up of some 186 instances of $之$ "it" revealed chaos. That of 51 實 "dividend," on the other hand, revealed a singular divide as

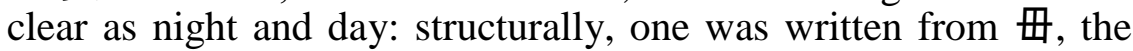
other from 尹; stylistically, the one featured sharp angles, an elongated end-stroke, and upward-slanted horizontal lines, while the other was round, stubby, and slumped to the right. We experienced

\footnotetext{
${ }^{11}$ See especially Matthias L. Richter, "Tentative Criteria for Discerning Individual Hands in the Guodian Manuscripts," in Rethinking Confucianism: Selected Papers from the Third International Conference on Excavated Chinese Manuscripts, Mount Holyoke College, April 2004, ed. Xing Wen 邢文 (San Antonio: Trinity University, 2006), 132-47; Li Songru 李松儒, Zhanguo jianbo ziji yanjiu: yi Shangbo jian wei zhongxin 戰國簡帛字跡研究: 以上博簡為中 心 (Shanghai: Shanghai guji chubanshe, 2015).

12 "Tentative Criteria," 138.

${ }^{13}$ Célestin X. Zhou 周霄漢 opened our eyes to this point in his talk "Preliminary Study on the Complete Collection of Detailed Annotation and Analogical Methods of the Nine Chapters (九章詳注比類算法大全) (1488), ” Université Paris Diderot, April 3, 2015. While 之 proved amenable to hand-differentiation in his earlier study of the Guodian 郭店 M1 * Laozi 老子 manuscripts, one notes that Richter later abandons it in his analysis of the Shanghai Museum *Min zhi fumu 民之父母: “*Min zhi fumu shows a considerable degree of variation in the shapes of even frequent characters (see the forms of $之$ listed below...), which are generally the most stable elements in an experienced hand. This variation, however, is certainly not caused by inexperience but is rather an intentional feature, written with much assurance by a skilled scribe" (The Embodied Text: Establishing Textual Identity in Early Chinese Manuscripts [Leiden: Brill, 2013], 36).
} 
similar luck with 有 “have,” 為 “make,”廣 “width,” and characteristics of left-right symmetry and end-strokes (Figure 3). Yes, a graph like 實 in this case occurs in fewer parts of the manuscript than does 之 (45 vs. 106 of 190 slips), but no one suggests dividing up hands based on a single graph.

The question was whether the day-and-night divide in other consistent orthographies like 有 coincided with that of 實. To determine if this were the case, we highlighted every occurrence of 實 in the PDF, assigning different colors to its divergent forms. Based on the working hypothesis that one does not change hands mid-slip, we highlighted the aforementioned forms where they occurred on the same slip as 實 to see if the one form of 實 occurs consistently (i.e. exclusively) with the one form of 有, 為, 廣, etc. It did. From there, we color-coded the divergent forms of the latter as per the former and proceeded to highlight their every occurrence. Thanks to a chain of only six criteria, in Figure 3, we were able to extend each color up and down the entirety of the manuscript, linking them to the A and B forms in Figure 1. Based on the working hypothesis that one does not change hands mid-section, we went back through to see if our color-breaks coincided with section and paragraph breaks, and, with but a few exceptions, they did, confirming that we were on to something with the criteria of consistency and coincidence. ${ }^{14}$

There were exceptions, but handwriting analysis is an iterative process. Starting with 實, the hypothesis that one does not change hands mid-slip happened to work, even if we know from the headings that this cannot be universally true. Had we started with 有, things would have been different, because while the vast majority of slips reveal a one-to-one correspondence of its A-form with the other A-forms in Figure 3, the nine slips 24, 39, 168-72, 175, and 180 mix forms. Having at first set these slips aside as "Group C," a second glance at the actual grouping of A- and B-forms on said slips revealed that it was no "mix" but, in each case, a mid-slip transition from B to A, except once, where it goes from A to B to A (below). The trick, in this case, would be to try different characters rather than throw out a perfectly useful working hypothesis. As to mid-section transitions, there too slips 168-71, 175, and 180 (plus 181-82) prove an exception, as do slips 24, 39, 101-4 and 162-63 (below). However, 64 of 69 sections do fall neatly to A or $\mathrm{B}$, so once again our working hypothesis was not so much disproved as it was proven useful for directing our attention to curious anomalies. A section-by-section breakdown is provided in the Appendix, and we will come to said anomalies shortly.

\footnotetext{
${ }^{14}$ A more detailed account of the steps described here was presented in Daniel Patrick Morgan, "On the Potential of Corpus-Based Handwriting Analysis: A Refined Analysis of the Zhangjiashan Tomb Library" (Scribal Hands and Scribal Practices in Manuscripts from Warring States and Early Imperial China, Universität Heidelberg, November 16, 2016), Universität Heidelberg.
} 


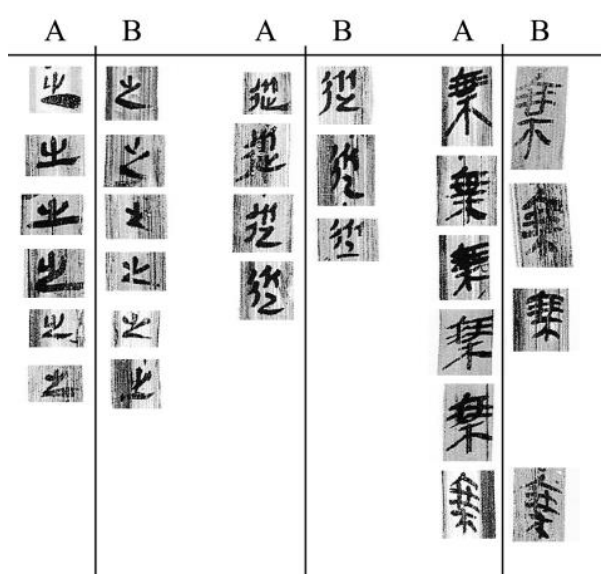

Figure 2: Unsuccessful criteria, Suan shu shu graphological analysis. Prevalent character forms such as these proved highly variable across $\mathrm{A}$ and $\mathrm{B}$ as identified via the stable character forms in Figure 3.

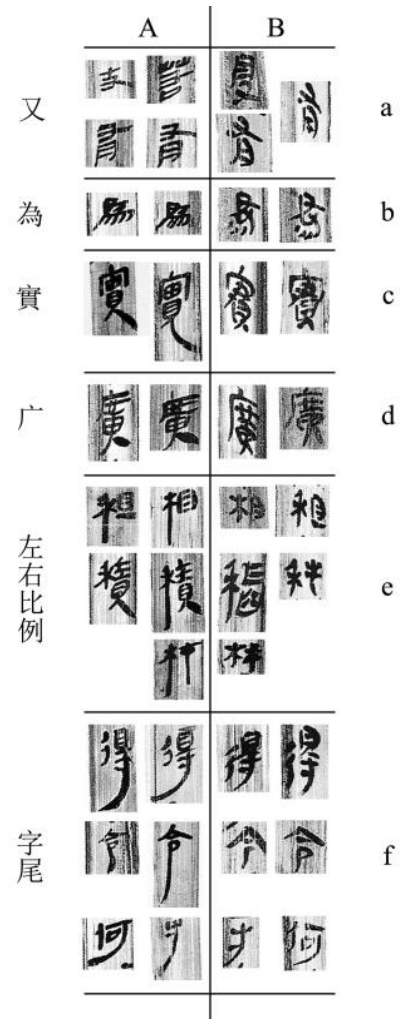

Figure 3: Successful criteria: (a) 又 component, angle, square vs. round; (b) 為; (c) 實, final stroke and composition (田 vs. 尹); (d) 廣, “feet” and component symmetry; (e) 木.禾 component symmetry; (f) exaggerated endstroke.

Returning to the matter of writing order, new information once again undermined our first hypothesis that $\mathrm{A}$ preceded $\mathrm{B}$. The fact that $\mathrm{B}$ headed 50 of 51 sections written by A seemed to imply that $B$ came last - thus "A" then "B", or "AB" — but various mid-slip and mid-section transitions place B first in a back-and-forth. The blame once again goes to "common sense," which led us to assume that there was a (simple) before and after. At this point, one begins to wonder if the body "must have" preceded the headings.

\section{Lower margin}

The lower margin of the Suan shu shu bears fourteen names: eleven instances of the surname "Yang" 楊 and three of "Wang" 王, one of each being in the form of “ $x$, already checked" 某已倠倠; the word jing 競 "contend" also appears once, just above the lower binding chord, where by context we can identify it as another name (Figure 4). As to what these are and why they are there, common sense would seem to dictate, as concluded by the editors of the 
Zhangjiashan M247 corpus, that they represent the "signatures" of "either the copyists or collators" (above).

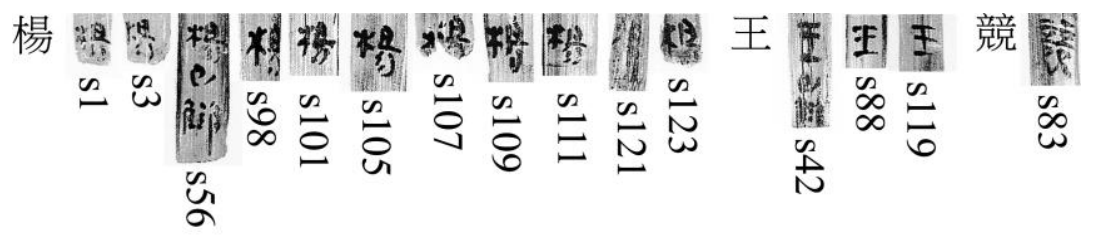

Figure 4: Lower-margin "signatures"

The problem, again, with this piece of common sense is that it is undermined by graphological analysis of primary sources. Namely, by comparing multiple documents "signed" by one and the same officer from Qin-Han administrative sites, Hsing I-t'ien 邢義田 and Enno Giele have shown evidence of the same "signature" appearing in different hands, which they attribute variously to the role of writing assistants (shuzuo 書佐), the copying of original documents, and so on. ${ }^{15}$ Whatever the exact reason in a given circumstance, Hsing and Giele remind us that it is not a given that our fourteen names are actually written by Yang, Wang, and Jing, nor that the latter are "either the copyists or collators."

Turning to our manuscript, one notes that we do see evidence of "checking" in that conspicuous errors are marked by dots. Take for instance the (unsigned) section 38, “Wu quan" 誤券 (Erroneously Inscribing on a Certificate), belonging to $\mathrm{B}:{ }^{16}$

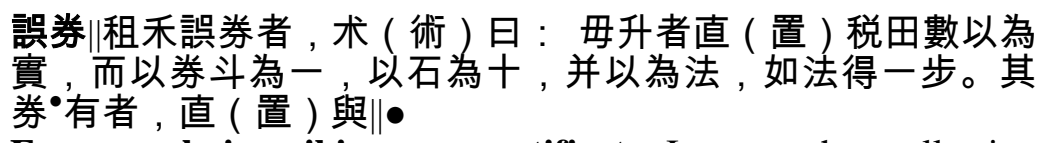

Erroneously inscribing on a certificate: In case, when collecting tax in millet, one erroneously inscribed (an amount) on a certificate, procedure: if there is no sheng (in the amount described), one puts (on the calculating surface) the number of the taxed cropland, taking this as dividend, and then taking each dou of the certificate as one; taking each dan as ten, one sums (the results) and takes (the result) as divisor. Dividing by the divisor yields the result in $b u$. In case on the certificate there are ${ }^{\bullet}$, one puts the allotted • (slip 93)

||田步數以為實, 而以券斗為一, 以石為十, 并以為法, 如法 得一步。其券有升者, 直 (置) 與 田步數以為實, 而以川 number of $b u$ of the (taxed) cropland, taking this as dividend, and then taking each dou of the certificate as one, and taking each dan

\footnotetext{
${ }^{15}$ See for example Hsing, "Handai jiandu gongwenshu de zhengwen, fuben, caogao he qianshu wenti” 漢代簡牘公文書的正文、副本、草稿和簽署問題, Guoli zhongyang yanjiuyuan lishi yuyan yanjiusuo jikan 國立中央研究院歷史 語言研究所集刊 83.4 (2011): 601-78, and Giele, “Signatures Of 'scribes' in Early Imperial China," Asiatische Studien/ Études Asiatiques 59.1 (2005): 353-

${ }^{16}$ For an argument on this and other dot-marked errors in the Suan shu shu, see our forthcoming article "Math Lessons: Towards an Interdisciplinary Approach to an Early Chinese Manuscript Culture" in Manuscript Cultures.
} 87. 
as ten, one sums (the results) and takes (the result) as divisor. Dividing by the divisor yields the result in $b u$. In case on the certificate there are sheng, one puts the number of $b u$ of the allotted cropland taking it as dividend, and then taking (slip 94).

$\|$ 券之升為一, 以斗為十, 并為法, 如・得一步。 $\rightarrow \|$ each sheng of the certificate as one, and taking each dou as ten, one sums (the results) to make the divisor. Dividing by the ${ }^{\bullet}$ yields the result in $b u$. II (slip 95)

Slip 94 repeats part of the contents of slip 93, starting from the character $⿴ 囗 十$, the main difference being the insertion of two characters omitted in the previous slip. First, "In case on the certificate there are", one puts..." (slip 93) is now "In case on the certificate there are sheng, one puts..." (slip 94). The procedure presents two cases: "If there is no sheng" and "In case on the certificate there are sheng." One is thus led to assume that the little dot marks an omission. This hypothesis is confirmed by the placement of the dot on slip 95, where a character is missing in the formulaic phrase “Dividing by the [divisor] yields the result in $b u$ ” 如〔法〕得一步. Second, in place of the unusual expression "the number of the taxed cropland" 税田數 on slip 93 we find, on slip 94, the more common expression "the number of $b u$ of the cropland" 田步數. What we have in each of these cases are mistakes, pure and simple, but that indicated by the dot in the body of slip 93 is the most detrimental for the understanding of the procedure, and the version on slip 94 corrects it. The big dot, in the lower margin, where we might expect the name of a "checker," would seem to highlight slip 93 as a faulty slip, and the fact that the faulty text is then corrected on the following slip suggests that that dot commanded this correction.

One finds a similar dot in the lower margin of the first slip of section 1, "Xiang cheng" 相乘 (Multiplying with Each Other), this time in conjunction with one of the "checker's" names:

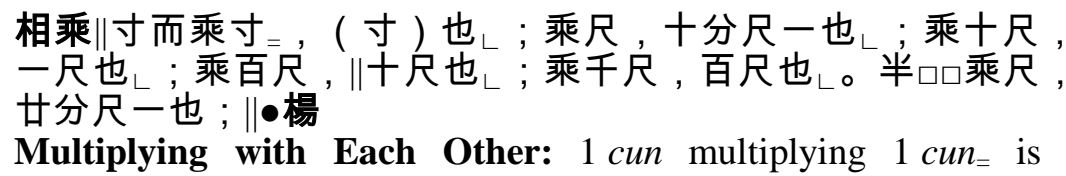
1 cun $_{\llcorner}$; multiplying 1 chi is $1 / 10$ chi $_{\llcorner}$; multiplying $10 \mathrm{chi}$ is 1 chi $i_{\llcorner}$; multiplying $100 \mathrm{chi}$ is $10 \mathrm{chi} i_{\llcorner}$; and multiplying $1000 \mathrm{chi}$ is $100 \mathrm{chi}_{\llcorner} .1 / 2$ [cun] multiplying $1 \mathrm{chi}$ is $1 / 20$ chi; •Yang (slip 1 )

$\|\llcorner$ 三分寸乘尺, 卅分尺一也 ; 八分寸乘尺, 尣 (八十) 分尺 $\left\llcorner 1 / 3\right.$ cun multiplying 1 chi is $1 / 30$ chi $i_{\llcorner} ; 1 / 8$ cun multiplying 1 chi is $1 / 80$ chi; II (slip 2)

\footnotetext{
\|半乘二, 半也 $\llcorner$; 乘半, 四分一也 也上; 乘半, 六分一也 \|楊

$1 / 2$ multiplying 1 is $1 / 2_{\llcorner}$; multiplying $1 / 2$ is $1 / 4_{\llcorner}$. $1 / 3$ multiplying $1_{\llcorner}$is $1 / 3_{\llcorner}$; multiplying $1 / 2$ is $1 / 6_{\llcorner}$; multiplying $1 / 3$ is $1 / 9_{\llcorner} .1 / 4$ multiplying 1 is Yang (slip 3)
} 
䏹分一也; 乘半，卅分尺一也。四分寸乘尺，冊分尺一川也； 五分寸乘尺，垔（五十）分尺一也；六分寸乘尺，交（六十） 分尺\|

$1 / 4$; multiplying $1 / 2$ is $1 / 30_{\llcorner}$. $1 / 4$ cun multiplying 1 chi is $1 / 30$ chi; $1 / 5$ cun multiplying 1 chi is $1 / 50$ chi; $1 / 6$ cun multiplying 1 chi is sixty parts $c h i$ (slip 4)

$\|$ 一也 $\llcorner$; 七分乘尺, 丰 (七十) 八分一也 一也 $\llcorner$; 乘四\|分，十六分一也 $\llcorner$ 。五分而乘一，五分一也 乘半, 十分一也\| one $(1 / 60 \text { chi })_{\llcorner} ; 1 / 7$ multiplying 1 chi is $1 / 78_{\llcorner}$; multiplying $1 / 3$ is $1 / 12_{\llcorner}$; multiplying $1 / 4$ is $1 / 16_{\llcorner} .1 / 5$ multiplying 1 is $1 / 5_{\llcorner}$; multiplying $1 / 2$ is $1 / 10$; (slip 5)

\|乘三分, 十五分一也 ; 乘四分, 廿分一也 分一也。\|乘分之术 (術) 日：母乘母為法, 子相乘為實。 $\rightarrow \|$ multiplying $1 / 3$ is $1 / 15_{\llcorner}$; multiplying $1 / 4$ is $1 / 20_{\llcorner}$; multiplying $1 / 5$ is $1 / 25$. Procedure for multiplying parts: denominator multiplying denominator makes the divisor; numerators multiplied with each other make the dividend. II (slip 6) ${ }^{17}$

Be it A or B, the Suan shu shu is fairly consistent in the use of a hook-mark "comma" $(\llcorner)$ to write down mathematical tables, using it to mark the end of every entry not terminating in a ligature. ${ }^{18}$ "Xiang cheng," presents us with such a table. This section, written by A, reveals a series of apparently unambiguous errors in slip 5: "1/7 multiplying 1 chi" should be $1 / 70$, not " $1 / 78$ "; immediately after, the implied operand also mysteriously changes from $1 / 7$ to $1 / 4$ ("multiplying $1 / 3$ is $1 / 12_{\llcorner}$; multiplying $1 / 4$ is $1 / 16$ "). If read as usual, this line, as written, is mathematically incorrect. Equally suggestive of an error is the order of presentation, which, within one and the same clause, flips between fractions with and without measuring units and interrupts otherwise neat progressions from 1 , to $1 / 2,1 / 3,1 / 4,1 / 5$, etc. Guo Shirong, Guo Shuchun, Ōkawa et al. and Joseph Dauben suggest we would expect this table to read in the following order:

【1】寸而乘寸 $=$ ，（寸）也 也；乘尺，十分尺一也 ；乘十尺， 一尺也 ；乘百尺，十尺也 ；乘千尺，百尺也

[Slip 1] 1 cun multiplying 1 cun is 1 cun $\llcorner$; multiplying 1 chi is $1 / 10$ ch $i_{\llcorner}$; multiplying 10 chi is 1 chi $i_{\llcorner}$; multiplying 100 chi is $10 \mathrm{chi} i_{\llcorner}$; and multiplying $1000 \mathrm{chi}$ is $100 \mathrm{chi} i_{\llcorner}$.

\footnotetext{
${ }^{17}$ Note that here and below we shall be rendering numbers in Arabic numerals for the sake of brevity, though the original does not obviously them in writing (nor in calculation).

${ }_{18}$ Other manuscripts use "leave-blank" paragraph break, with multiple registers, for the same purpose. For details, see Chemla, "Texts for Tables in ancient Chinese mathematical writings: From Qin-Han manuscripts textual tables to Song-Yuan diagrammatic tables", (presented at a workshop on Tables in scholarly Chinese sources, Université Paris Diderot, March 22-23, 2012), article forthcoming.
} 
【...1】半吅乘尺, 廿分尺一也 ；【2a】三分寸乘尺, 姍分 尺一也 ;【4c】四分寸乘尺，刪分尺一也上; 五分寸乘尺， 垔 (五十) 分尺一也 ; 六分寸乘尺, 交 (六十) 分尺【5a】 一也 ; 七分乘尺, 丰 (七十)【4b】分尺一也レ; 【2b】八 分寸乘尺, 尣( 八十) 分尺一也。

[Slip 1 cont.] 1/2 [cun] multiplying 1 chi is $1 / 20$ chi $i_{\llcorner}$; [slip 2a] $1 / 3$ cun multiplying 1 chi is $1 / 30$ chi $i_{\llcorner}$; [slip 4c] $1 / 4$ cun multiplying 1 chi is $1 / 40$ chi $i_{\llcorner}$1/5 cun multiplying 1 chi is $1 / 50$ chi $i_{\llcorner}$; $1 / 6$ cun multiplying 1 chi is $1 / 60$ chi ${ }_{\llcorner}$; [slip 5a] $1 / 7$ cun multiplying 1 chi is $1 / 70$ [slip 4b] chi ${ }_{\llcorner}$; [slip 2b] 1/8 cun multiplying 1 chi is $1 / 80$ chi. IIII

【3】半乘一，半也 ; 乘半，四分一也 。 三分而乘一七，三 分一也 ; 乘半，六分一也 ; 乘三分，九分一也

[Slip 3] $1 / 2$ multiplying 1 is $1 / 2\llcorner$; multiplying $1 / 2$ is $1 / 4\llcorner .1 / 3$ multiplying $1\left\llcorner\right.$ is $1 / 3\left\llcorner\right.$; multiplying $1 / 2$ is $1 / 6_{\llcorner}$; multiplying $1 / 3$ is $1 / 9\llcorner$.

【...3】四分而乘一，【4a】四分一也 ; 乘半，【5b】八分 之一也 ; 乘三分，十二分一也

[Slip 3 cont.] 1/4 multiplying 1 is [slip 4a] 1/4; multiplying $1 / 2$ is [slip 5b] $1 / 8$; multiplying $1 / 3$ is $1 / 12_{\llcorner}$; multiplying $1 / 4$ is $1 / 16_{\llcorner}$. [s]

【...5b】五分而乘一，五分一也 ；乘半，十分一也 $\llcorner; 【 6 】$ 乘三分，十五分一也 ；乘四分，廿分一也 ；乘五分，廿五 分一也

[Slip 5b cont.] $1 / 5$ multiplying 1 is $1 / 5_{\llcorner}$; multiplying $1 / 2$ is $1 / 10$; [slip 6] multiplying $1 / 3$ is $1 / 15_{\llcorner}$; multiplying $1 / 4$ is $1 / 20_{\llcorner}$; multiplying $1 / 5$ is $1 / 25$.

Ōkawa et al. and Dauben suggest that the present order of the Suan shu shu's table is the result of its being uncritically sight-copied from an original in which the slips had become disordered, as per Figure 5 (Hypothetical original B). ${ }^{19}$ This is entirely possible, but it is difficult to understand why, in this case, the copyist would copy

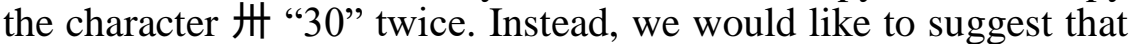
the mistake here might rather be a matter of eye skipping: that the copyist missed a line and, as precedented in slips 93-94 (above), he/she restarted the text further down beginning with the character prior to the omission (Figure 5, Hypothetical original A). The duplication of $\mathrm{O}$ in this case (and $\mathbb{\theta}$ in slip 94) may serve as some sort of signal - a signal of the place, earlier on, from which the inserted text was omitted. Whatever the case may be, "Checker" Yang's dot in the lower margin of slip 1 seems also to mark a problem, be it a defective section or a defective copy to be amended. Whatever the case may be, furthermore, the immediate reaction to the correctors' dots in the body of both "Xiang cheng" (A)

${ }^{19}$ Chōkazan Kankan Sansūsho kenkyūkai, Kankan Sansūsho, 152-56; Dauben, "Suan Shu Shu, a Book on Numbers and Computations," 102-8. Previously, Peng Hao simply cleans up the text as it is written via appeal to "redundant text" 衍文 and “missing characters" 脫字; see Zhangjiashan Han jian Suan shu shu zhushi, 37-40; cf. Cullen, Writings on Reckoning, 35-36, 117. 


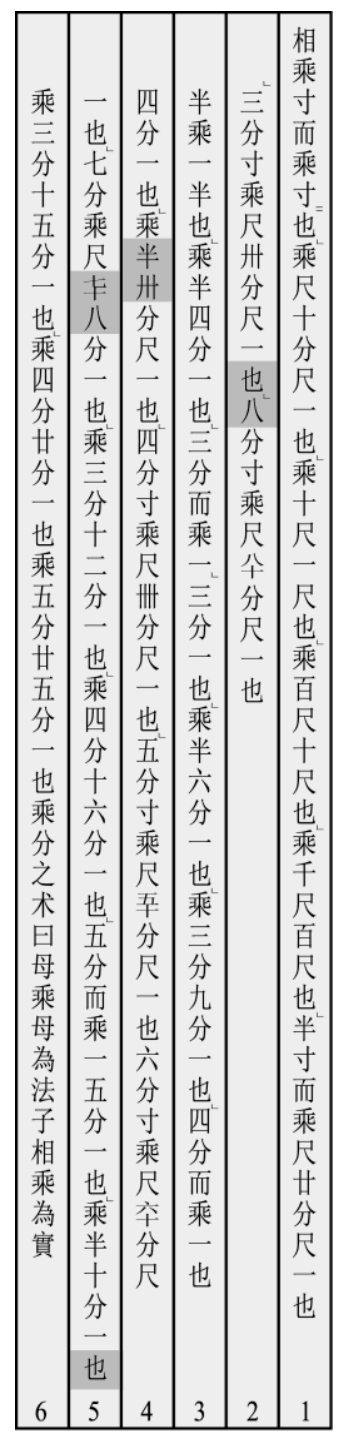

Suan shu shu (copy)

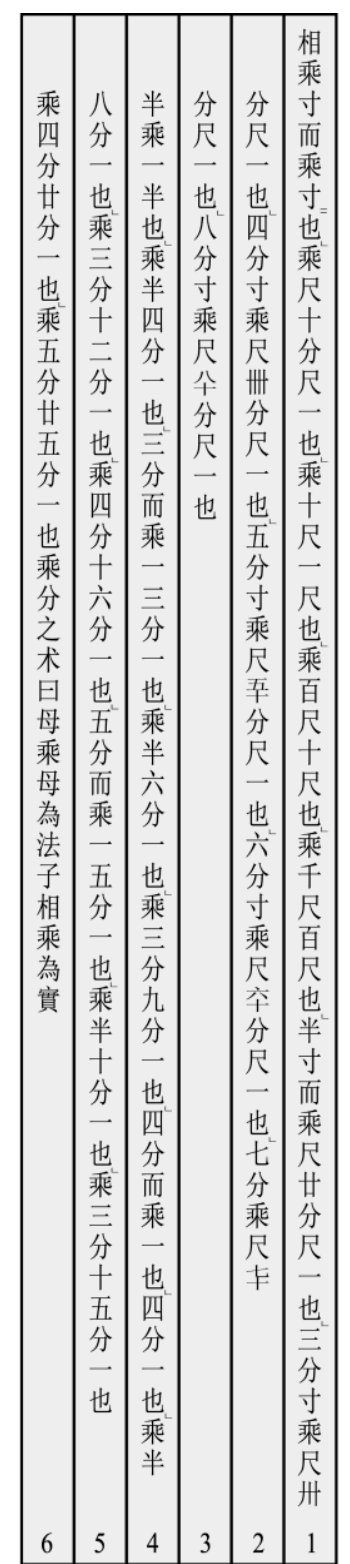

Hypothetical original

A

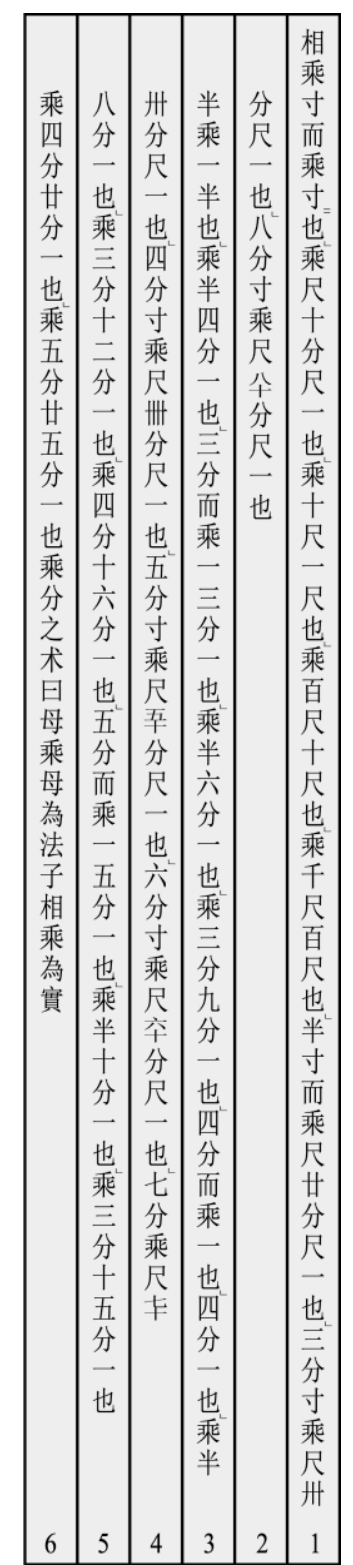

Hypothetical original

B

Figure 5: Attempt to explain the textual order of the "Xiang cheng" table. With hypothetical original A, the Suan shu shu copyist's eye skips from slip 1 to 3 in the original. Alerted to his/her mistake by "Checker" Yang's dot midway through, the copyist then abruptly inserts the missing text from slip 2 in the middle of slip 4 (starting from the first character prior to the omission, 冊 " 30 "), before continuing with slip 5. Alternatively, with hypothetical original $\mathrm{B}$, there is a misplaced slip in the original (slip 4, which should go between 1 and 2), and the copyist for some unknown reason copies 册 "30" twice (once between original slips 1 and 2 and a second time at the beginning of the original slip 4). Dark gray indicates serious mid-slip ruptures in the Suan shu shu's textual order. 
And "Wu quan" (B) indicate that there was a back-and-forth interaction between the actors involved in the production and the correction of the text. ${ }^{20}$

Returning to the question of handwriting, there is not much to say about the "signatures." In total, as per Figure 4, we have fifteen "signatures" in nineteen characters presenting us but five graphs to compare: 楊, 王, 競, 已, and 倠隹. This is not a lot to go on, particularly for a simple character like 王 or 已, so we must leave the question open. What we can say is that there is no obvious correlation between "checking" and "hands," as Yang, Wang, and dots appear equally under A and B. What we can also say is that that the Suan shu shu was not a personal creation but a group enterprise involving at least three to five people in a considerable back-andforth of writing, proofreading, and correction.

\section{The larger corpus}

Given the number of people apparently involved in the production of the Suan shu shu, we thought next to ask whether A or B characters occurred anywhere else in the Zhangjiashan M247 tomb library. The matter of identifying "hands" across multiple texts is a different proposition than separating them in one, of course, so we were forced to further modify our approach. ${ }^{21}$

We call this our approach to corpus-based handwriting analysis "fingerprinting." At its core, "fingerprinting" is based on the same criteria of consistency and correlation, described above, as concerns "characteristics" 特征 (Li Songru) like those selected in Figure 3. "Fingerprinting" relies on Li's concept of ziji 字迹 (lit. "character traces") as a sort of neutral ground between "scripts," "scriptors," and "hands" that refers only to a writing sample discernable from others by means of common characteristics. It also takes the following of Li's propositions as axiomatic:

The same scriptor can write different ziji, but identical ziji are definitely written by the same scriptor. ${ }^{22}$

Every person's [zi]ji is/are distinct from every other in its ensemble, which is to say that people are all different in terms of the sum or system of their [zi]ji characteristics, and not that an individual's every character and every stroke are unique. ${ }^{23}$

\footnotetext{
${ }^{20}$ Chemla and Morgan, "Math Lessons", op. cit., discusses all the dots. For more on the topic of textual corruption in early mathematical texts, see Daniel Patrick Morgan, "What Good's a Text? Textuality, Orality, and Mathematical Astronomy in Early Imperial China," Archives internationales d'histoire des sciences 65.2 (2015): 51-74.

${ }^{21}$ The following is based on Morgan, "On the Potential of Corpus-Based Handwriting Analysis."

${ }_{22}^{22}$ Li Songru, Zhanguo jianbo ziji yanjiu, 42.

${ }^{23}$ Li Songru, Zhanguo jianbo ziji yanjiu, 36; citing Jia Yuwen 賈玉文 and Zou Mingli 㮲明理, Zhongguo xingshi kexue jishu daquan: wenjian jianyan 中 國刑事科學技術大全·文件檢驗 (Beijing: Zhongguo renmin gongan daxue chubanshe, 2002), 105.
} 
"Fingerprinting" starts with differentiation, breaking individual manuscripts into ziji like the A and B of Suan shu shu. Next comes identification. The first step of identification is compiling comparable "fingerprints" for each ziji, like the A and B columns of Figure 3, which one places together in a single table. From there, one separates the A's, B's, and C's already determined to differ and sorts the columns of one's table until it looks something like Figure 6.

As to differentiation, the Gai Lu 蓋盧, *Lipu 曆譜, Mai shu 脈 書, and Yin shu 引書 revealed no evidence of multiple ziji, while the * Qiance 遣策 proved so short and difficult to read to provide us with a meaningful sample. The Suan shu shu, as we saw, can be divided into A and B. The Ernian lüling 二年律令 has already been divided into A, B, and C ziji by Li Jingrong 李婧嶸, ${ }^{24}$ and our own color-coding via different criteria returned more or less exactly the same result. Lastly, we were to divide the Zou yan shu 奏獻 書 likewise into A, B, and C ziji. A section-by-section breakdown of the multi-ziji manuscripts can be found in the Appendix.

As to identification, we began first with a process of elimination. Zouyan shu A, for example, is rather unique in its semi-circle endstroke on 也, its orthography for 為, its parallel, curving lines on 而, and its inward-curving 今, let alone that it is only one of two $z i j i$ to cross 其 with a $\times$. Taken together- "in its ensemble"-it is clearly different from the other ziji in Figure 6. After eliminating six other ziji as incommensurable in this manner, we were left with five that eluded categorical differentiation: (1) *Lipu, (2) Suan shu shu B, (3) Gai Lu, (4) Mai shu, and (5) Zouyan shu C. As to identification, the links between these five samples differ in strength. That between Suan shu shu B and Gai Lu is the strongest, given that they share a peculiar pinch at the corner of 其, the same orthography for 為, the same inward curl in the bend of 而, and the same imperfectly crossed 五. That between these and the Mai shu is somewhat weaker, because the Mai shu is written in a different "style" or "script," featuring thin, elongated strokes and the old Qin orthography for 也; still, Mai shu shares enough of their peculiarities to identify it with the same hand. Lastly, the *Lipu and Zouyan shu $\mathrm{C}$ offer smaller samples for comparison, but there the 為, 而, 五, and other forms are a perfect match. Whatever this means for the other ziji, we can conclude that the *Lipu, Suan shu shu B, Gai Lu, Mai shu, and Zouyan shu C were written by the same person. As to what that means, only a ziji-informed reading of said texts can tell us; we, as per our competencies, shall focus on the Suan shu shu.

\footnotetext{
24 "The Ernian Lü Ling Manuscript" (Ph.D. diss., Universität Hamburg, 2014), 33-50.
} 


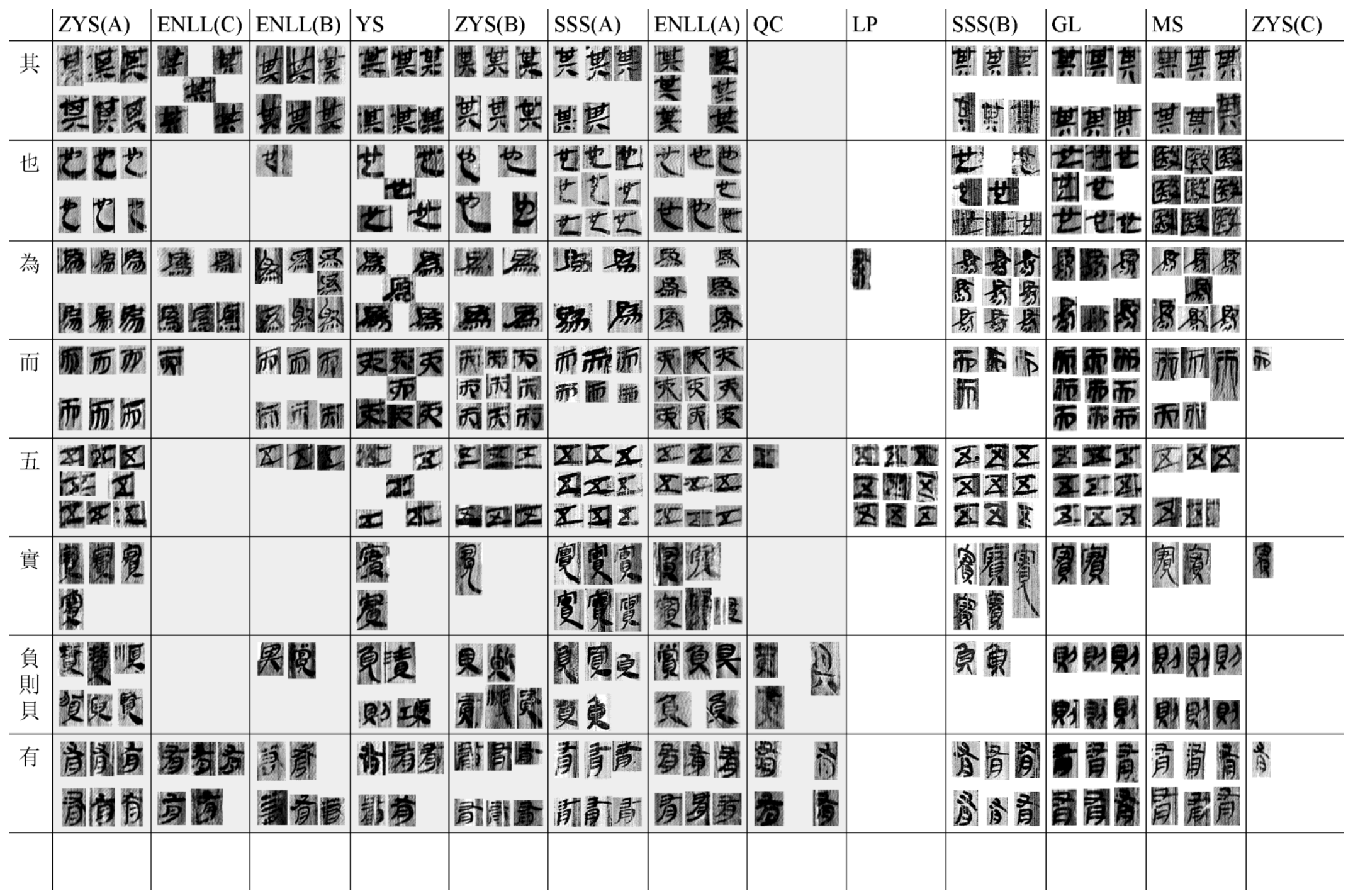

Figure 6: "Fingerprint database" for Zhangjiashan M247. ENLL = Ernian lüling; GL = Gai Lu; LP = *Lipu; MS = Mai shu; QC = *Qiance; SSS = Suan shu shu; YS = Yin shu; ZYS = Zouyan shu. 


\begin{tabular}{|c|c|c|c|c|c|c|c|c|c|c|c|c|c|}
\hline & ZYS(A) & |ENLL(C) & |ENLL(B) & YS & ZYSS(B) & $\mid \operatorname{SSS}(\mathrm{A})$ & |ENLL(A) & QC & LP & SSS(B) & GL & MS & ZYS(C) \\
\hline 人 & 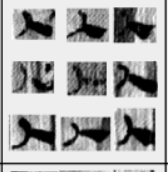 & Whe & $\begin{array}{ll}m \\
M\end{array}$ & 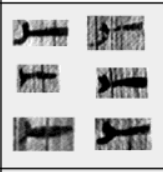 & 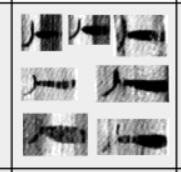 & $\begin{array}{l}K \\
H \\
H\end{array}$ & $\begin{array}{l}m-1 \\
m-1\end{array}$ & & & ted & H & 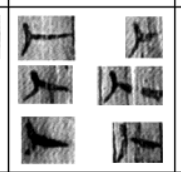 & $\begin{array}{l}\mathbf{N} \\
\mathrm{N} \\
\mathbf{K}\end{array}$ \\
\hline 得 & 軘得得 & 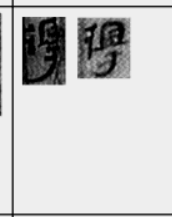 & 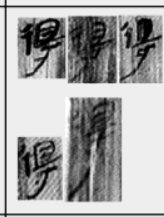 & 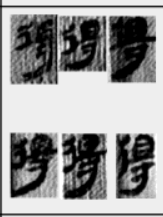 & 得 & 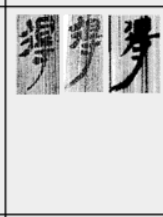 & \begin{tabular}{|l|} 
得期得 \\
得瀑㑩
\end{tabular} & & & 得得得 & $\begin{array}{l}\text { 得行 } \\
\text { 得 }\end{array}$ & 19 & \\
\hline $\begin{array}{l}\text { 令 } \\
\text { 命 }\end{array}$ & 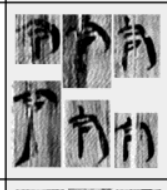 & & & 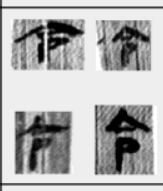 & 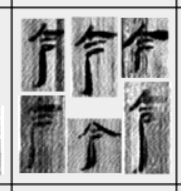 & & 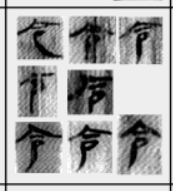 & & & 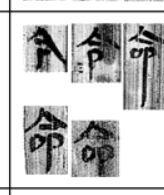 & 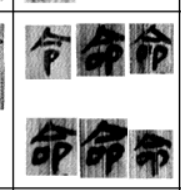 & & \\
\hline $\begin{array}{l}\text { 見 } \\
\text { 先 }\end{array}$ & 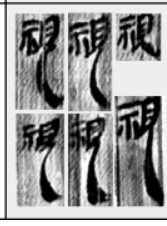 & In: & & 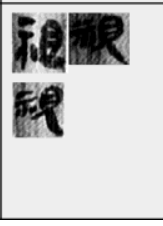 & 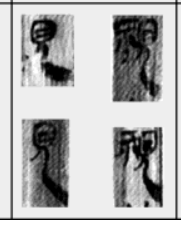 & & 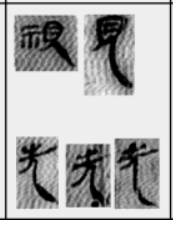 & & & E & 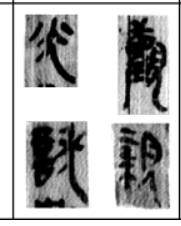 & 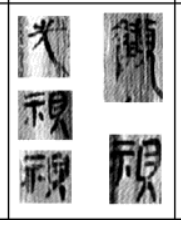 & \\
\hline
\end{tabular}

Figure 6 (cont.) 


\section{Handwriting Distribution}

Suan shu shu Hand B appears throughout the Zhangjiashan M247 corpus, so it is on B that we should focus our attention. Of all the places where this hand appears, moreover, it is the Suan shu shu that is the most promising in terms of answers to what this means. We say this because mathematical texts offer a distinct advantage over, say, philosophy, medicine, and law in that in mathematics we can be sure of what is an error and of the type of error it is, variora being the surest guides to understanding the process by which a given manuscript was composed. It is to this end that we return to the Suan shu shu for answers about the larger corpus.

As to Suan shu shu A and B, in the body, out of 190 slips, A accounts for $118(62 \%)$, and B for $58(31 \%)$, the two alternating variously $\mathrm{AB}, \mathrm{BA}$, and $\mathrm{ABA}$ on another 9 slips $(5 \%) .{ }^{25}$ Their specific distribution by section is as per Table 2 in the Appendix.

It was originally our thought that graphology might aid in reconstructing the manuscript's section-order, but that it did not do. As regards the manuscript's contents, the mid-section, mid-slip, and heading-body alternation of hands only worsened the problem of each section's textual and codicological independence. As regards the slips, nothing stands out about their distribution in the "Excavated Position Diagram" except that B is largely concentrated near the bundle's center. ${ }^{26}$ Desperate, one of us traveled to the Jingzhou Museum in September 2014 at the invitation of Director Emeritus Peng Hao to see what if anything was on the back of these slips. The verso, it turns out, is covered in reverse impressions: discolored ellipsoid patches of varying length and width, their size, shape, and discoloration recalling the patchwork fading that one observes in photographs of the recto-fading that may not be a product of time or erasure but transfer. Some of these traces were very clear and might potentially aid in elucidating the section order or restoring defective text. ${ }^{27}$ Sadly, other than the title slip, there are no photographs of the verso, and we were not allowed to take them out of concern for the manuscript's preservation.

It was also originally our thought that graphology might reveal some greater internal divide in the manuscript's contents, and there we fared a little better. In terms of contents, there are several patterns to be discerned from the distribution of A and B ziji. As concerns mathematical topics, B generally writes all sections dealing

\footnotetext{
${ }^{25}$ Note that five slips have eluded our identification, mostly for reasons of physical damage.

${ }^{26}$ See Mo Zihan and Lin Lina, "Ye you lunzhe xiede," 243-45.

${ }^{27}$ See Thies Staack, "Yuelu Qin jian Wei yu deng zhuang si zhong juance yi de bianlian: yiju jianbei huaxian he jianbei fanyin ziji fuyuan juanzhou yuanmao" 㺟麓秦簡『蒍獄等狀四種』卷冊一的編聯——依據簡背劃線和簡背反印字 跡復原卷軸原貌, trans. Li Jingrong 李婧嶸, Hunan daxue xuebao (zhehui kexue ban) 湖南大學學報 (社會科學版 ) 27.3 (2013): 20-25; “Identifying Codicological Sub-Units in Bamboo Manuscripts: Verso Lines Revisited," Manuscript Cultures 8 (2015): 157-86.
} 
with croplands and weaving, while to A, exclusively, go all sections relating to volumes, cash, the circle-square relationship, and elementary arithmetic (i.e., computations with fractions and measurement units). As concerns text-type, and relating to his/her monopoly on the elementary arithmetic, to A go also the numerical tables (tables for computations with powers of ten, with fractions, with measurement units, etc.). There are (apparent) exceptions to these generalizations, which we will explore below, but suffice it to say for now that this breakdown leads to an altogether more noteworthy observation. ${ }^{28}$ Namely, to B go all the meta-statements on procedures - the theory - and this is reflected in terminological differences between ziji. Only with $\mathrm{B}$, for instance, do we find statements referring to a class of problems like "One assesses the norms about other things like this" 程它物如此 (slip 87). Only with $\mathrm{B}$, do we find comparisons between procedures such as "Detaching the length is likewise like this” 啓從 (縱) 亦如此 (slip 159) or "Restoring this (original value) is like the procedure for detaching the width” 復之, 如啓廣之术（術） (slip 186). Only with B, lastly, do we see a concern for how the inverse operation restores ( $f u$ 復) the quantity with which one started-an abstraction interpreted as essential by later commentators to The Nine Chapters of Mathematical Procedures (Jiuzhang suanshu 九章算術). ${ }^{29}$

\section{Reading Hand-transitions in the Suan shu shu}

The number and distribution of hands in the Zhangjiashan M247 corpus is interesting, but the key to the story they have to tell lies in the pattern of their transition. In this section, we turn to an examination of those sections of the Suan shu shu that witness alternation and what that alteration tells us about the nature of the manuscript and the relationship between its creators.

\section{“Shao guang” 少度 (Reducing the Width)}

The section "Shao guang" deals with dividing the area of a rectangular cropland (always $1 \mathrm{mu}$ 畧) by a width whose value has systematically the same form (integer + a sequence of fractions) to find its length. Paragraph 1, written by B, opens with an abstract,

\footnotetext{
${ }^{28}$ As regards mathematical topics, one notes that "Fen dang ban zhe" 分當半 者 presents us with an apparent exception in that it features $B$ writing on elementary arithmetic. That said, "Fen dang ban zhe" echoes another section by Hand A ("Fen ban zhe" 分半者), which suggests a relationship of guidance or correction as that we will examine in “Shao guang” 少廣, “Qi zong”啟縱, and "He fen" 合分, as studied below. As regards layout, these same sections-“Fen dang ban zhe," "Shao guang," and "He fen"-are likewise exceptional in that they feature $B$ writing numerical tables, but here, once again, the exception would seem to be contained to the back and forth of guidance and/or correction. The section "Hao" 耗 presents an additional exception in this regard, which we examine in Chemla and Morgan, "Math Lessons."

${ }^{29}$ Karine Chemla and Guo Shuchun, Les neuf chapitres: le classique mathématique de la Chine ancienne et ses commentaires (Paris: Dunod, 2004), esp. 924-25.
} 
general procedure describing the operations necessary to solve the problem without specifying any numerical values. Paragraphs $2-10$, which all begin with "If below there is" 下有, use said procedure to prescribe operations and give results for successive width-values, from $1+1 / 2 b u$ to $1+1 / 2+1 / 3+1 / 4+1 / 5+1 / 6+1 / 7+1 / 8+1 / 9$ $+1 / 10 \mathrm{bu}$. In terms of layout, paragraph 1 is prose, while paragraphs $2-10$ can all be decomposed into two parts: a numerical table specific to the solution of the problem, whose "cells" are divided by hook $(\llcorner)$ and ligature marks $(=)$, and whose sum is noted at the end; and a second part, in prose, which completes the solution. ${ }^{30}$ In terms of ziji, paragraph 2 also goes to $\mathrm{B}$, the interesting part starting in paragraph 3 ( $\mathrm{A}$ is indicated in bold):

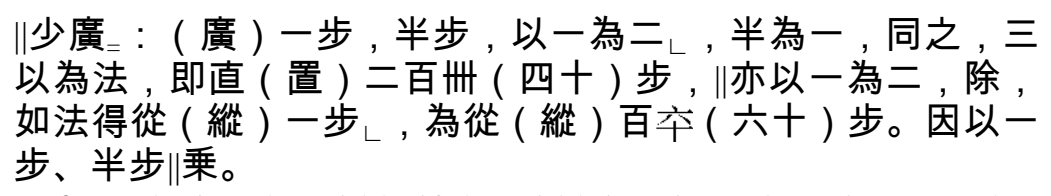

[प[ 2] Reducing the width: if the width is $1 b u$ and $1 / 2 b u$, one takes 1 as $2\llcorner, 1 / 2$ as 1 ; summing these gives 3 , which is taken as divisor. One hence places $240 \mathrm{bu}$, and likewise one takes 1 as 2 . Eliminating (dividing), when it is like the divisor, it yields, for the length, $1 b u$ (i.e., dividing by the divisor yields the length in $b u)_{\llcorner}$, which makes, for the length, $160 \mathrm{bu}$. Accordingly, multiplying [this] by $1 \mathrm{bu}$ and 1/2 bu [makes a cropland of $1 \mathrm{mu}$. I] (slip 167)

\section{$\|$ 下有三分, 以一為六, 半為三 $=$, (三) 分為二, 同之, 十一 $\|$, 得從 (縱) 百卅步有 (又) 十一分步之十, 乘之田一畧。 $\rightarrow \|$}

[प 3] [Since] below there is $\mathbf{1 / 3}$, one takes 1 as $6,1 / 2$ as $3_{=}$, and $1 / 3$ as 2; summing these [gives] 11, yielding, for the length, $130 \mathrm{bu}$ and $10 / 11 \mathrm{bu}$. Multiplying this [gives] a cropland of $1 \mathrm{mu}$. II (slip 168)
$\|$ 下有四分, 以一為十二 $\llcorner$, 半為六, 三分為四 $=$, (四) 分為 三，同之廿五。得從 (縱) 百一十川五步有 (又) 廿五分步之 五 , 乘之田一畧。 $\rightarrow \|$

[प[ 4] [Since] below there is $1 / 4$, one takes 1 as $12_{\llcorner}, 1 / 2$ as $6 ; 1 / 3$ as $4_{=}$, and $1 / 4$ as 3 ; summing these [gives] 25 , yielding, for the length, $115 \mathrm{bu}$ and 5/25 $\mathrm{bu}$. Multiplying this [gives] a cropland of $1 \mathrm{mu}$. II (slip 169)

But for three exceptions in this series (II 2, II 3 and II 9), the alternation B $\rightarrow$ A occurs consistently at “one gets" 得, i.e. at the transition between table and prose, for the end of the solution. To understand the significance of the exceptions, of course, we must first explain the rule.

\footnotetext{
${ }^{30}$ We thank Zhu Yiwen 朱一文 for first identifying the first part of each paragraph of "Shao guang" as a table.
} 


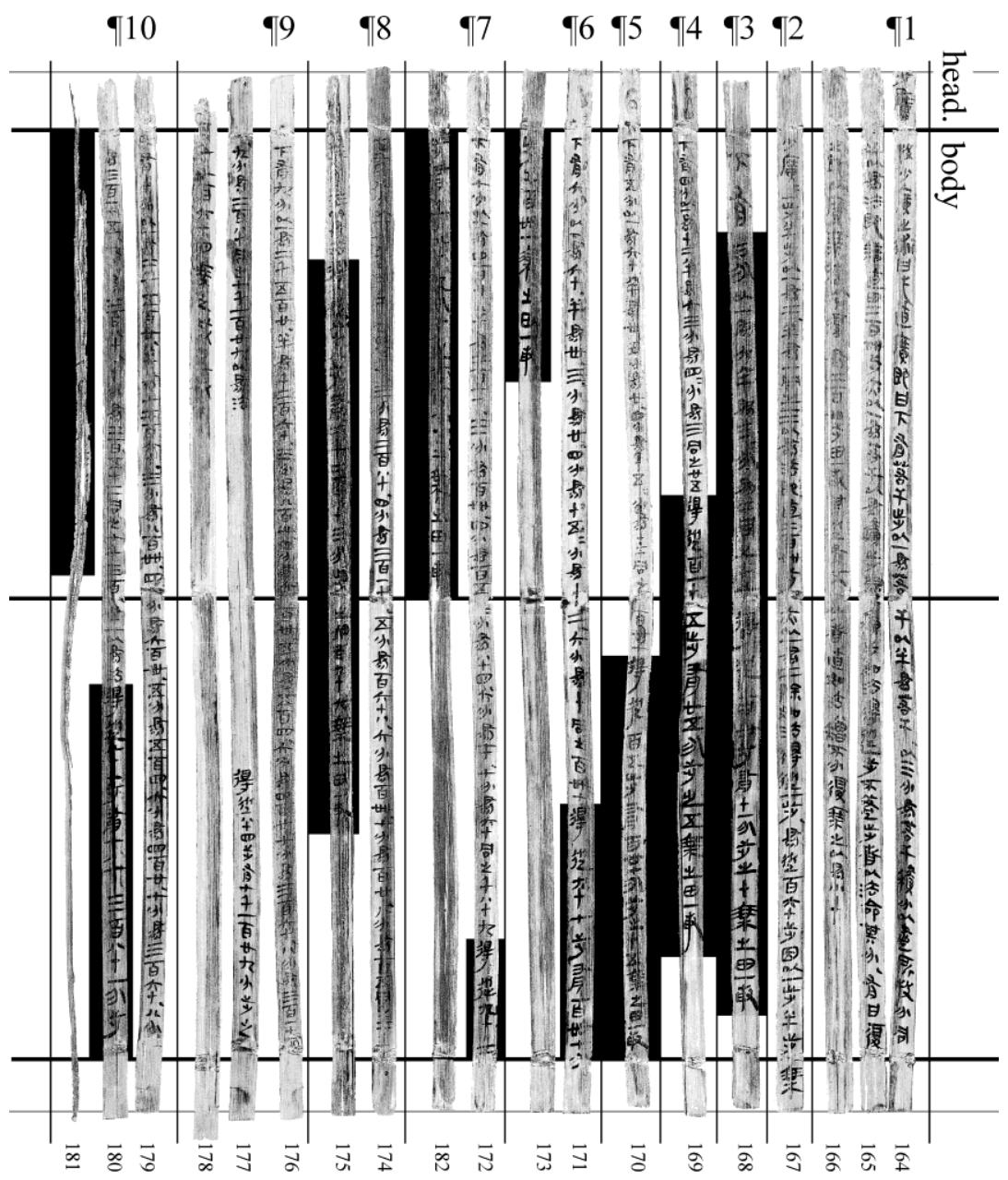

Figure 7: Alternation of scribal hands in "Shao guang" (black highlighting represents A).

The computations referred to in the prose part of paragraphs 310 follow the model established by $\mathrm{B}$ in paragraphs 1 and 2 . The prose of paragraphs 3-10, however, systematically omits several steps of calculation. This is not the case in the version of "Shao guang" preserved in the Yuelu Academy manuscript Shu 數, slips 160-71, which is otherwise identical with the Suan shu shu down to the level of formatting. More precisely, the Suan shu shu's paragraph 2 , written exceptionally by $\mathrm{B}$, is identical with the corresponding paragraph in Shu. ${ }^{31}$ Moving forward, and into A, however, compare paragraph 4 (above) to the following line from $S h u$ (square brackets mark the Suan shu shu's elisions):

$\|$ 下有四分, 以一為十二 $\llcorner$, 【以】半為六【 $\backslash$ ，三分為四 $=$, (四) 分為三, 同之廿\|五, 【以為法。直 (置) 二百冊步, 亦以一為十二, 為二千八百尣 (八十 ) 捗】。

\footnotetext{
${ }^{31}$ It is identical, that is, except that for this paragraph of "Shao Guang" Shu does not refer to the procedure for reverse computation.
} 
[Since] below there is $1 / 4$, one takes 1 as $12,\llcorner$ [one takes] $1 / 2$ as 6 , $1 / 3$ as $4_{=}$, and $1 / 4$ as 3 ; summing this [gives] 25 , [which is taken as divisor. One places $240 \mathrm{bu}$, and likewise one takes 1 as 12 , which makes 2880 bu.] (slip 161)

\|【除之, 如法得一步，】為從 ( 縱 ) 百一十川五步有 ( 又 ) 廿 五分步之五，成一\|㑼。 $\rightarrow \|$

[Eliminating (dividing) from this, when it is like the divisor, it yields $1 b u$ (i.e., dividing by the divisor yields the result in $b u$ )], which makes, for the length, $115 \mathrm{bu}$ and 5/25 bu, which generates

$1 \mathrm{mu}$. II (slip 162)

In other words, in most paragraphs the opposition between ziji corresponds with both an opposition between forms of text (table/prose) and an opposition between ways of writing (full/abridged). With this in mind, it would seem that the reason that $\mathrm{B}$ wrote the entirety of the first problem was to provide a model for A to follow in subsequent solutions. B even seems to have sought to make this model fit into a single strip (as is suggested by the text exceptionally written well into the lower margin, and the missing characters at the end). However, although A computed along these lines, A only wrote the end part of the solution in abridged form. Moreover, in all the subsequent paragraphs, B continues to write the table part needed for the solution, and A jumps in to record the result of the problem computed on this basis. All of this seems overly complex to believe that one person did this, so here we can probably make the leap to say that A and B are different people writing in alternation.

This leap is confirmed by the exceptions that we encounter in their pattern of hand-alternation. The first exception is paragraph 3, slip 168, where A takes over after "[Since] below there is," which is written in such an exaggerated fashion, as you can see in Figure 7, as if to signal something like "now you fill out the rest." The second exception is paragraph 9, slip 177, which, where we would expect A, gives us instead $\mathrm{a} \approx 10 \mathrm{~cm}$ blank followed by an abridged ending by $B$ running $\approx 8 \mathrm{~cm}$ onto the next slip. The top of slip 178 is damaged, but based on the position of the writing and binding marks, it would appear to subtended $\approx 7 \mathrm{~mm}$ below the surrounding slips. Slip 178 is a different size, which suggests that it was inserted into the manuscript (by B) for the sake of containing the additional $\approx 8 \mathrm{~cm}$ of the solution. Considering that the $\approx 8 \mathrm{~cm}$ of the solution on slip 178 would have easily fit in the $\approx 10 \mathrm{~cm}$ blank on slip 177, the extra slip is unnecessary, and would thus must seem to signal something on behalf of B, i.e. "you left this blank, I am filling it out for you."

\section{Other transitions}

“Qi zong” 啟縱 (Revealing the Length) tells a similar story. Like "Shao guang," "Qi zong" (slips 160-63) deals with finding a side of a rectangular field given the area and the other side. The differ- 
ence is the numerical values involved, and thus the procedures differ accordingly. Like "Shao guang," "Qi zong" also begins with $\mathrm{B}$, but the transition to A occurs here on a new line (slip 162). In paragraph 1 (slips 160-61), B begins with a complete formulation of the problem, without giving an answer, after which B provides a procedure $(s h u)$ describing the key operations necessary to solve it. From there, B turns to a procedure for "restoring" ( $f u$ 復) the given area via reverse calculation from the solution and, as a sort of conclusion, B then reiterates the key steps of the procedure from a more theoretical perspective. In paragraph 2 (slips 162-63), we have two problems in abridged form with answers followed by the prescription of how to execute the key operations for specific values such as those given in said problems. This type of procedure is reminiscent of "Shao guang" paragraph 2. It derives from the procedure formulated by B, but, this time, it is written by A. In other words, $\mathrm{A}$ is translating into actions what $\mathrm{B}$ gave as operations. ${ }^{32}$

We also see B intervening to correct A, as appears to be the case in the section "He fen" 合分 (Joining Parts), on slips 21-25. "He fen" is about adding fractions, and the procedures it contains oppose cases of fractions that share a common denominator with those that do not. The section begins with A offering a general rule in three parts:

\section{.... $\ldots$ 母相類，子相從 ; 母不相類，可倍 $=$, (倍 ) ; 可三 $=$, (三)... $\|. .\| 【 .21 】 \| \ldots$ 其不相類者，母相乘為法，子互乘 $\|$ 母并 以為實 $=$, ( 實 ) 如法成一。 ... || 【22】}

If the denominators are of the same category as one another, the numerators join one another (i.e., are added to one another); if the denominators are not of the same category, one doubles $=$ the [denominators] that it is fitting to double, and one triples= those that it is fitting to triple... In case the corresponding denominators are [still] not of the same category, denominators multiplying one another make the divisor; numerators multiplying the denominators that do not correspond to them (i.e., the remaining denominators) are summed to make the dividend $=$; one divides the dividend by the divisor. (slips 21-22).

Rule in hand, A then poses a problem pointing back to the opening before giving the solution: “The procedure is as to the right" 其術 如右方 (slip 23). Finally, A poses a problem involving a division whose dividend contains two fractions and formulates a procedure $(s h u)$ for solving it. This is where B steps in. Interestingly, B formulates two separate procedures for adding fractions, insisting on their separation:

\footnotetext{
32 This latter procedure yields the pattern of computation to be followed. Interestingly, like B in "Shao guang" paragraph 2, A feels the need to inscribe the procedure within the space of a single slip, slip 163 being the only other slip whose writing extends into the lower margin to achieve this aim.
} 
$\|\ldots\| \ldots$ 有曰：母乘母為法 $\llcorner ， 子$ 羡乘母 $\|$ 【24】\|為實 $=$ ，（實 ） 如法而一 $\llcorner$ 。其一日：可十= $(十)$, 可九 $=($ 九 ) ... 相類止 ᄂ。母相類，子相從。\|【25】

There is one saying: denominators multiplying denominators make the divisor; numerators multiplying the denominators that do not correspond to them (i.e., the remaining denominators) make the dividend $_{=}$; one divides the dividend by the divisor $\llcorner$. Another one says: when it is fitting to ten-uple $=$, one ten-uples; when it is fitting to nine-uple $=$, one nine-uples... One stops when the denominators are of the same category as one another $\llcorner$. When the denominators are of the same category as one another, the numerations join one another. (slips 24-25)

Here, B's first procedure essentially repeats the end of the previous block quote by A, while the second goes back to the middle of A's procedure. It would seem that $B$ is driving a distinction here between two procedures that A has conflated, but, whatever his intentions, B is clearly stepping in to at least add to A's presentation.

Another AB transition occurs in "Bai hui" 粺毁 (Bai and Hui), on slips 98-104, the appearance of the name Yang below both A and B (slips 98 and 101) and a dot within A's body pointing more clearly to evidence of correction. "Bai hui" is a table of two-part entries comprising, first, a statement asserting equivalences between fractional quantities of different types of grain and, second, one or two procedures accounting for the initial statement. For instance, paragraph 1 (A, slips 98-100) treats conversion from hulled grain ( $m i$ 米) and wheat (mai 麦) into bai and hui, beginning "hulled grain: 1/3 sheng makes bai [hulled grain], 3/10 sheng" 米少半升為粺十分升之三 (slip 98) and, then, adding a rule of three that yields this result. The aforementioned dot occurs between the statement and the procedure within the third entry of this type (slip 98), after which, interestingly, all further entries by A insert another procedure, before the rule of three, narrating the calculation of "numerators" ( $z i$ 子) and "denominators" ( $m u$ 母). The hypothesis that the dot signals A to add this previously omitted procedure is corroborated by the composition of paragraph 2 (B, slips 101-4), which treats conversion out of bai and hui, thus providing the other half of the equation: in this paragraph, B provides only procedures of the latter type. Here again, two observations lend to the impression that $\mathrm{B}$ is more experienced than $\mathrm{A}$ : first, B uses more complicated numbers than does $\mathrm{A}$, switching from units of $1 / 3$ to $1 / 4$; second, $B$ is more systematic in the use of the hook-mark "comma" as per the standard formatting of such a table.

One last transition occurs in "Fu mi" 負米 (Carrying Hulled Grain), on slips 38-39, this one being a little harder to understand. Here, four characters matching B (bold) appear in the middle of a sentence by A: "One places a unit, and per customs, one thrice doubles it to make the divisor. Again one places 1 dou of hulled grain...”直 (置) 一關而参 (三) 倍為法, 有 ( 又) 直 (置) 米一斗 (slip 39). This could be an instance of alternation, but it 
could also be a correction, by $\mathrm{B}$, or a product of graphic interference, on the part of A, in copying something from B. This transition requires further study (dai kao 待考).

\section{Conclusion}

One of the original goals of our work on the Suan shu shu was to shed light on how we might restore the order of its sections, and, in that sense, our study was a failure. Rather than reveal the beforeand-after of two coherent blocks of writing, our graphological analysis lead us instead to a lively back-and-forth-a back-andforth between heading and body, between paragraphs in a single section, and between lines on a single slip. The archeological diagram only made things worse; if we had photographs of the verso, we might well be able to solve this problem, but in the meantime we will probably never know in what order to put the sections like "Wu quan" and "Shao guang" studied here.

Instead, we found something infinitely more interesting-a community of people - and we were able to trace one member of that community through most of the rest of the Zhangjiashan M247 corpus. Before speculating about what that means, allow us, in a few words, to reiterate how we got there. We did not get there by common sense and twenty-first-century inferences about what scribes "must have done"- that, if anything, consistently sent us in the wrong direction vis-à-vis our primary source. There are a lot of things that "must have happened" with the Suan shu shu that, oddly, never did. Instead, we got there by starting over, several times, eliminating as many of assumptions as possible. The challenge was not to imagine the complete range of possibilities that might explain a given phenomenon but to come up with essential contentions that could be tested and, preferably, falsified. "Must have" statements, where they cannot be tested, belong on the other side of a cordon sanitaire.

One of the things you hear when working on a tomb text is that it's pointless, because your text is “[just] a mingqi 明器," a massproduced "fake" bought from a funerary workshop with no relation to the tomb occupant or to the manuscript culture of the living. We know that there are "real" things in tombs, and there are certain manuscripts that we exempt from this charge, so the question of mingqi is one that scholars tend to approach on a case-by-case basis. ${ }^{33}$ As concerns Zhangjiashan M247, Robin Yates and Anthony Barbieri-Low argue than the legal texts cannot be "actual working documents": the Ernian lüling, because it is full of "errors" that

\footnotetext{
${ }^{33}$ The argument that certain tomb texts could be mingqi originates with Enno Giele, "Using Early Chinese Manuscripts as Historical Source Materials," Monumenta Serica 51, no. 1 (2003): 409-38, and Hsing I-t'ien 邢義田, Di bu ai bao: Handai de jiandu 地不愛寶 : 漢代的簡牘 (Beijing: Zhonghua shuju, 2011), 150. For a forceful argument to the contrary, see Alain Thote, "Daybooks in Archaeological Context," in Books of Fate and Popular Culture in Early China: The Daybook Manuscripts of the Warring States, Qin, and Han, ed. Donald J. Harper and Marc Kalinowski (Leiden: Brill, forthcoming).
} 
"would have been proofread," and the Zouyan shu, because it contains "some bamboo slips that appear to have been reused from other texts." 34 Instead, they offer that "the Zhangjiashan legal texts, and most of the other medical and mathematical texts from the tomb, either were produced in a scriptorium as practice texts and later sold as funerary products for burial or were copied in a funerary workshop specifically for inclusion in a burial." 35 The assumption behind this either-or is that tomb texts cannot have anything to do with tomb occupants, or some of them, that is.

No one questions a "calendar" or "journal" like the *Lipu as not having belonged to the tomb occupant, because such a document is generally the most personal in the entire tomb. It is in the *Lipu, for example, that we read "[I] Xin/newly surrendered to the Han" 新降為漢 in 202 B.C.E. (slip 2) and “[I] retired from office due to illness" 病免 in 194 B.C.E. (slip 10); it is from the final year of the *Lipu, moreover, that we date the sealing of Zhangjiashan M247 to $\geq 186$ B.C.E. ${ }^{36}$ Yates and Barbieri-Low, for one, treat the *Lipu as revelatory of the Zhangjiashan M247 tomb occupant's dates, activities, and name (Xin 新). ${ }^{37}$ As such, any evidence that a portion of the Zouyan shu was written by the same person as the *Lipu should significantly impact our either-ors. So too should any demonstration that that very handwriting matches one party in the lively back and forth in the Suan shu shu. If this is the work of a funerary workshop it all seems oddly elaborate and personal; if these are school texts, we might consider the possibility that the tomb occupant was the teacher.

The hand that wrote "[I] Xin/newly surrendered to the Han" and "[I] retired from office due to illness" is the same as that we find in the Suan shu shu beginning solutions for the other person to complete, establishing models for the other person to follow, and inserting spaces and whole slips into the manuscript just, apparently, to make a point. If the objects with which he was buried be any guide, the tomb occupant-Xin, Hand B-would have certainly had the time and experience necessary to do some teaching around 186 B.C.E.: he had retired eight years earlier, and the turtledove staff with which he was buried places him at $>70$ years of age. ${ }^{38}$ Elements of this connection are speculative-yes, there may be

\footnotetext{
${ }^{34}$ Law, State, and Society, 106-7. Notes that by the criteria of "would have been proofread" (p. 106), the Suan shu shu does meet one of Yates and BarbieriLow's criteria of discerning an "actual working document." Note also that $d e$ spite proofreading, in this case, the text remains abbreviated, disordered, and mathematically defective in places.

${ }^{35}$ Law, State, and Society, 107. The idea that the Ernian lüling might represent a school text is proposed in Nagata Hidemasa 永田英正, “Chōkazan Kankan Ninen ritsuryō no jitai ni tsuite no shokan” 張家山漢簡『二年律令』 の字体についての所感, Chōko ryūiki bunka kenkyūjo nenpō 長江流域文化研 究所年報 4 (2006): 1-5. On manuscript school texts, see 王海城 Wang Haicheng, Writing and the Ancient State: Early China in Comparative Perspective (Cambridge: Cambridge University Press, 2014), 275-300.

${ }^{36}$ See n. 1 above.

${ }^{37}$ Law, State, and Society, 48.

${ }^{38}$ Li Jingrong, "The Ernian Lü Ling Manuscript," 9-10, 63-64; BarbieriLow and Yates, Law, State, and Society, 106, 842-843n10.
} 
another explanation for the Suan shu shu; yes, an assistant could have written everything; and, yes, a funerary workshop pulled off an elaborate hoax - but surely this line of speculation promises a more compelling story. As to what that story is, of course, one would have to give a ziji-informed read to the other manuscripts in this tomb. Here, we are hardly qualified to speak for the historian off medicine, philosophy, or law, so let us invite you, the reader, to pick up here, where we leave off. 


\section{Appendix}

\begin{tabular}{|c|c|c|c|c|}
\hline No. & Heading & & $z i j i$ & slips \\
\hline 1 & 相乘 & Multiplying with Each Other & A & $1-6$ \\
\hline 2 & 分乘 & Multiplying Parts & A & 7 \\
\hline 3 & 乘 & Multiplying & A & $8-12$ \\
\hline 4 & 增減分 & Increasing or Decreasing Parts & A & 13 \\
\hline 5 & 分當半者 & When Parts Should be Halved & B & $14-15$ \\
\hline 6 & 分半者 & If Parts are Halved & A & 16 \\
\hline 7 & 約分 & Simplifying Parts & A & $17-20$ \\
\hline \multirow[t]{2}{*}{8} & 合分 & Joining Parts & A & $21-24$ \\
\hline & & & B & $* 24-25$ \\
\hline 9 & 徑分 & Direct Sharing & A & $26-27$ \\
\hline 10 & 出金 & Paying out Gold & A & $28-31$ \\
\hline 11 & 共買材 & Buying Timber in Common & A & $32-33$ \\
\hline 12 & 狐出關 & The Fox Goes Through a Customs-post & A & $34-35$ \\
\hline 13 & 狐皮 & The Fox's Skin & A & $36-37$ \\
\hline \multirow[t]{3}{*}{14} & 負米 & Carrying Hulled Grain & A & $38-39 *$ \\
\hline & & & B & *39 \\
\hline & & & A & *39 \\
\hline 15 & 女織 & Woman Weaving & B & $40-42$ \\
\hline 16 & 並租 & Levying Tax Together & B & $43-45$ \\
\hline 17 & 金價 & The Price of Gold & A & $46-47$ \\
\hline 18 & 春粟 & Hulling Unhulled Grain & A & $48-49$ \\
\hline 19 & 銅耗 & Bronze Wastage & A & $50-51$ \\
\hline 20 & 傳馬 & Post Horses & A & $52-53$ \\
\hline 21 & 婦織 & Woman Weaving & B & $54-56$ \\
\hline 22 & 羽矢 & Feathering Arrows & A & $57-58$ \\
\hline 23 & 漆錢 & Lacquer Money & A & $59-60$ \\
\hline 24 & 繒幅 & Silken Strip & A & $61-63$ \\
\hline 25 & 息錢 & Interest Money & A & $64-65$ \\
\hline 26 & 飲漆 & Pouring [Water] into Lacquer & A & $66-67$ \\
\hline 27 & 税田 & Taxed Field & B & $68-69$ \\
\hline 28 & 程竹 & Regulations for Bamboo & A & $70-71$ \\
\hline 29 & 醫 & The Doctor & A & 72 \\
\hline 30 & 石率 & Computing a unit price for the $S h i$ & A & $74-75$ \\
\hline 31 & 賈鹽 & Pricing Salt & A & $75-77$ \\
\hline 32 & 絲練 & Undressed and Dressed Silk Fiber & A & 78 \\
\hline 33 & 㧝脂 & Worked Fat & A & $79-82$ \\
\hline 34 & 取程 & The Norms for Collecting & B & $83-85$ \\
\hline 35 & 耗租 & Wastage on Tax & B & $86-87$ \\
\hline 36 & 程禾 & Regulations for Cereal Plants & A & $88-90$ \\
\hline 37 & 取㠍程 & The Norm for Collecting Hemp & B & $91-92$ \\
\hline 38 & 誤券 & Erroneously Inscribing on a Certificate & B & 93-95 \\
\hline 39 & 租誤券 & $\begin{array}{l}\text { When Taxing, Erroneously Inscribing } \\
\text { on a Certificate }\end{array}$ & B & $96-97$ \\
\hline \multirow[t]{2}{*}{40} & 粺毀 & $B a i$ and $H u i$ & A & $98-100$ \\
\hline & & & B & 101-104 \\
\hline 41 & & Wastage & B & $105-108$ \\
\hline 42 & 粟爲米 & Unhulled Grain becomes Hulled & B & $109-110$ \\
\hline 43 & 粟求米 & Seeking Hulled from Unhulled Grain & A & $111-112$ \\
\hline 44 & 粟求米 & Seeking Hulled from Unhulled Grain & A & $113-114$ \\
\hline 45 & 米求粟 & Seeking Unhulled from Hulled Grain & A & $115-116$ \\
\hline 46 & 米粟並 & Hulled and Unhulled Grain Together & A & $117-118$ \\
\hline 47 & 粟米並 & Unhulled and Hulled Grain Together & A & 119 \\
\hline- & & unidentified & ? & $120-121$ \\
\hline- & & unidentified & B & 122 \\
\hline- & & unidentified & ? & 123 \\
\hline- & & unidentified & B & 124 \\
\hline- & & unidentified & ? & 125 \\
\hline 48 & 負炭 & Carrying Charcoal & A & $126-128$ \\
\hline
\end{tabular}




\begin{tabular}{|c|c|c|c|c|}
\hline 49 & 籚笏 & Bamboo Tubes & A & $129-130$ \\
\hline 50 & 羽矢 & Feathering Arrows & A & 131 \\
\hline 51 & 行 & Travelling & A & 132 \\
\hline 52 & 分錢 & Sharing Cash & A & 133-134 \\
\hline 53 & 米出錢 & Paying out Money for Hulled Grain & A & $135-140$ \\
\hline 54 & 除 & $\begin{array}{l}\text { Chu (Path to a tomb, for a geometric } \\
\text { solid) }\end{array}$ & A & $141-142$ \\
\hline 55 & 塹堵 & $\begin{array}{l}\text { Qian } d u \text { (Wall on a moat, for a geo- } \\
\text { metric solid) }\end{array}$ & A & 143 \\
\hline 56 & 媰 & Chu (Straw, for a geometric solid) & A & $144-145$ \\
\hline 57 & 旋粟 & Making Unhulled Grain into a Cone & A & $146-147$ \\
\hline 58 & 困蓋 & Qun gai (A Granary Cover, for a cone) & A & 148 \\
\hline 59 & 圆亭 & $\begin{array}{l}\text { Yuan ting (A Round Pavilion, for a } \\
\text { truncated cone) }\end{array}$ & A & $149-150$ \\
\hline 60 & 井材 & $\begin{array}{l}\text { Jing cai (A Timber [Shaped Like] a } \\
\text { Well, for a cylinder) }\end{array}$ & A & $151-152$ \\
\hline 61 & 以圆材方 & Cutting a Square from a Circle & A & 153 \\
\hline 62 & 以方材回 & Cutting a Circle from a Square & A & $154-155$ \\
\hline 63 & 園材 & A Circular Timber & A & $156-157$ \\
\hline- & & unidentified & ? & 158 \\
\hline 64 & 啓廣 & Detaching the Width & B & 159 \\
\hline \multirow[t]{2}{*}{65} & 啓縱 & Detaching the Length & B & $160-161$ \\
\hline & & & A & $162-163$ \\
\hline \multirow[t]{14}{*}{66} & 少廣 & Reducing the Width & B & $164-168$ \\
\hline & & & A & *168 \\
\hline & & & B & 169 \\
\hline & & & A & *169 \\
\hline & & & B & 170 \\
\hline & & & A & $* 170$ \\
\hline & & & B & 171 \\
\hline & & & A & *171-172 \\
\hline & & & B & 172 \\
\hline & & & A & $* 172,182$ \\
\hline & & & B & $174-175$ \\
\hline & & & A & $* 175$ \\
\hline & & & B & $176-180$ \\
\hline & & & A & *180-181 \\
\hline 67 & 大廣 & The Greater Width & B & 183-184 \\
\hline 68 & 方田 & Determining the Side of a Square Field & B & $185-186$ \\
\hline 69 & 里田 & Making a Field into $\mathrm{Li}$ & $\mathrm{B}$ & $187-190$ \\
\hline
\end{tabular}

Table 2: Distribution of hands in the Suan shu shu. Mid-slip transitions marked by *. Note that this table is revised from Mo Zihan and Lin Lina, "Ye you lunzhe xiede," 2423. Grey highlighting indicates those portions of the body that we suspect were written by the tomb occupant.

\begin{tabular}{lrrrl}
\hline No. & Heading & ziji & slips \\
\hline 1 & 賊律 & Statutes on Assault & A & $1-50$ \\
& & & B & $51-53$ \\
2 & 盜律 & Statutes on Robbery & A & 54 \\
& & B & $55-57$ \\
& & A & 58 \\
& & B & $59-60$ \\
& & A & 61 \\
& & B & $62-63$ \\
& & A & $* 63$ \\
& & B & 64 \\
& & A & $65-66$ \\
& & B & $67-73$ \\
& & A & $74-79$ \\
\hline
\end{tabular}




\begin{tabular}{|c|c|c|c|c|}
\hline \multirow{5}{*}{3} & \multirow{5}{*}{ 具律 } & \multirow{4}{*}{ Statutes on the Composition of Judgements } & $\mathrm{B}$ & 80 \\
\hline & & & A & 81 \\
\hline & & & A & $82-99$ \\
\hline & & & B & 100 \\
\hline & & & A & $* 100-125$ \\
\hline 4 & 告律 & Statutes on Denunciations & A & 126-136 \\
\hline 5 & 捕律 & Statutes on Arrest & A & $137-156$ \\
\hline \multirow[t]{5}{*}{6} & 亡律 & Statutes on Abscondence & A & $157-163$ \\
\hline & & & B & \\
\hline & & & A & 165-171 \\
\hline & & & B & 172 \\
\hline & & & A & 173 \\
\hline \multirow[t]{2}{*}{7} & 收律 & Statutes on Impoundment & $\mathrm{C}$ & 174-176 \\
\hline & & & A & 177-181 \\
\hline \multirow[t]{5}{*}{8} & 襍律 & Statutes on Miscellaneous Matters & B & $182-183$ \\
\hline & & & A & 184-190 \\
\hline & & & B & 191-193 \\
\hline & & & A & *193 \\
\hline & & & B & 194-196 \\
\hline 9 & 錢律 & Statutes on Cash & A & 197-209 \\
\hline \multirow[t]{2}{*}{10} & 置吏律 & Statutes on the Establishment of Officials & A & $210-220$ \\
\hline & & & $\mathrm{C}$ & $221-224$ \\
\hline 11 & 均輸律 & Statutes on Equalizing Transportation & A & $225-228$ \\
\hline 12 & 傳食律 & $\begin{array}{l}\text { Statutes on Food Rations at Conveyance Sta- } \\
\text { tions }\end{array}$ & A & $228-238$ \\
\hline 13 & 田律 & Statutes on Agriculture & A & $239-257$ \\
\hline 14 & 關市律 & Statutes on Passes and Markets & A & $258-263$ \\
\hline 15 & 行書律 & Statutes on the Forwarding of Documents & A & $264-277$ \\
\hline 16 & 復律 & Statutes on Exemption from Taxes & A & $278-281$ \\
\hline 17 & 賜律 & Statutes on Bestowals & A & 282-304 \\
\hline \multirow[t]{7}{*}{18} & 戶律 & Statutes on Households & A & $305-330$ \\
\hline & & & $\mathrm{C}$ & $331-333$ \\
\hline & & & A & $334-341$ \\
\hline & & & $\mathrm{C}$ & 342 \\
\hline & & & A & 343 \\
\hline & & & $\mathrm{C}$ & 344 \\
\hline & & & A & $345-346$ \\
\hline 19 & 效律 & Statutes on Checking & A & $347-353$ \\
\hline 20 & 傅律 & Statutes on Enrollment & A & $354-366$ \\
\hline 21 & 置後律 & Statutes on Establishment of Heirs & A & $367-391$ \\
\hline 22 & 爵律 & Statutes on Ranks & $\mathrm{B}$ & $392-395$ \\
\hline 23 & 興律 & Statutes on Levies & A & $396-406$ \\
\hline 24 & 徭律 & Statutes on Government Service & A & $407-417$ \\
\hline 25 & 金布律 & Statutes on Finance & A & $418-439$ \\
\hline 26 & 秩律 & Statutes on Salaries & A & $440-473$ \\
\hline 27 & 史律 & Statutes on Scribes & A & $474-487$ \\
\hline 28 & 津關令 & Ordinances on Fords and Passes & A & $488-526$ \\
\hline
\end{tabular}

Table 2: Distribution of hands in the Ernian lüling. Mid-slip transitions marked by *. Distribution is as per Li Jingrong, "The Ernian lü ling Manuscript," 33-50, with the exception of slip 333, which we switched from A to C. Note that Group C appears to us as the leftovers of dividing the manuscript into $\mathrm{A}$ and $\mathrm{B}$, and we hesitate from ascribing it the same the same graphological integrity binding the others. 


\begin{tabular}{llcl}
\hline No. & Heading & $z i j i$ & slips \\
\hline 1 & *The Absconding Indigenous Conscript & A & $1-7$ \\
2 & *The Absconding Female Slave & A & $8-16$ \\
3 & *The Eloping Lovers from Qi & A & $17-27$ \\
4 & *A Mutilated Man Unwittingly Marries an Absconder & A & $28-35$ \\
5 & *Sword Fight between a Runaway "Slave" and a Thief Catcher & A & $36-48$ \\
6 & *Beating to Death an Illegally Held Slave & A & $49-50$ \\
7 & *A Crooked Widow Tries to Cheat Her Runaway Slaves & A & $51-52$ \\
8 & *A Male Slave Escapes and a Border Guard is Punished & A & 53 \\
9 & *Falsifying the Account Books (1) & A & $54-55$ \\
10 & *Falsifying the Account Books (2) & A & $56-57$ \\
11 & *Counterfeiting a Horse Passport & A & $58-59$ \\
12 & *A Delay in Forwarding Documents & A & 60 \\
13 & *A Small Bribe Results in a Large Fine & A & $61-62$ \\
14 & *A Judiciary Scribe Harbors an Unregistered Person & A & $63-68$ \\
15 & *A County Magistrate Robs Grain & A & $69-74$ \\
16 & *A County Magistrate Orders the Murder of a Judiciary Scribe & B & $75-84$ \\
& A & $85-98$ \\
17 & *A Successful Appeal of a Conviction Gained by False Accusa- & B & $99-123$ \\
& tion and Torture & & \\
18 & *The Benevolent Magistrate and the Chu Insurgency & A & $124-145$ \\
& & C & $146-148$ \\
& *Shi You Solves the Case of Hair and Grass in the Lord's Food & A & $149-161$ \\
19 & B & $162-173$ \\
20 & *An Assistant Scribe Robs Grain and Confucian Principles & B & $174-179$ \\
21 & *A Scribe of the Commandant of the Court Overturns a Sen- & B & $180-196$ \\
& tence for Illicit Intercourse & & \\
22 & *A Cunning Scribe Solves a Robbery and Attempted Murder & A & $197-221$ \\
& & B 222-226 \\
& & A & $227-228$ \\
\hline
\end{tabular}

Table 3: Distribution of hands in the Zouyan shu. Given the absence of headings or obvious section titles in this manuscript, we have opted for Barbieri-Low and Yate's titles only. Grey highlighting indicates those portions of the body that we suspect were written by the tomb occupant. 